\title{
Motor Inhibition Affects the Speed But Not Accuracy of Aimed Limb Movements in an Insect
}

\author{
Delphine Calas-List, ${ }^{1}$ Anthony J. Clare, ${ }^{1}$ Alexandra Komissarova, ${ }^{2}$ Thomas A. Nielsen, ${ }^{1}$ and Thomas Matheson ${ }^{1,2}$ \\ ${ }^{1}$ University of Leicester, Department of Biology, Leicester LE1 7RH, United Kingdom, and ${ }^{2}$ Department of Zoology, University of Cambridge, Cambridge \\ CB2 3EJ, United Kingdom
}

\begin{abstract}
When reaching toward a target, human subjects use slower movements to achieve higher accuracy, and this can be accompanied by increased limb impedance (stiffness, viscosity) that stabilizes movements against motor noise and external perturbation. In arthropods, the activity of common inhibitory motor neurons influences limb impedance, so we hypothesized that this might provide a mechanism for speed and accuracy control of aimed movements in insects. We recorded simultaneously from excitatory leg motor neurons and from an identified common inhibitory motor neuron $\left(\mathrm{CI}_{1}\right)$ in locusts that performed natural aimed scratching movements. We related limb movement kinematics to recorded motor activity and demonstrate that imposed alterations in the activity of $\mathrm{CI}_{1}$ influenced these kinematics. We manipulated the activity of $\mathrm{CI}_{1}$ by injecting depolarizing or hyperpolarizing current or killing the cell using laser photoablation. Naturally higher levels of inhibitory activity accompanied faster movements. Experimentally biasing the firing rate downward, or stopping firing completely, led to slower movements mediated by changes at several joints of the limb. Despite this, we found no effect on overall movement accuracy. We conclude that inhibitory modulation of joint stiffness has effects across most of the working range of the insect limb, with a pronounced effect on the overall velocity of natural movements independent of their accuracy. Passive joint forces that are greatest at extreme joint angles may enhance accuracy and are not affected by motor inhibition.
\end{abstract}

Key words: accuracy; aimed limb movement; inhibition; insect; joint stiffness; reaching

\section{Introduction}

The accuracy of aimed limb movements can be controlled by regulation of limb stiffness and viscosity (Hogan, 1985; Selen et al., 2006, 2009; Wong et al., 2009), which are governed by neuromuscular properties and reflexes. In humans, increased cocontraction of antagonist muscles (and thus joint stiffness) enhances movement accuracy (Gribble et al., 2003; Popescu et al., 2003 ) by filtering out the deleterious effects of signal-dependent noise in the motor command (Osu et al., 2004). However, many aimed movements instead show a tradeoff between accuracy and speed (Woodworth, 1899; Fitts, 1954). When making fast, accu-

Received May 23, 2013; revised Feb. 28, 2014; accepted April 18, 2014.

Author contributions: T.M. designed research; D.C.-L. and A.K. performed research; D.C.-L., A.J.C., A.K., T.A.N., and T.M. analyzed data; D.C.-L. and T.M. wrote the paper.

This work was supported by Biotechnology and Biological Sciences Research Council Grant BB/C005538/1 (T.M.) and Research Development Fellowship BB/I019065/1 (T.M.) and a Welcome Trust Value in People Award (D.C.-L.). We thank the staff of the Joint Biomedical Workshops, University of Leicester, for designing and constructing the electronic laser controller and optical couplings, Donna Sharples for technical assistance, and Maurice Andrews and Rachel Lockley for maintenance of the locust colony. We thank Julia Stalleicken and DaeEun Kim for their contributions to the early stages of development of the locust preparation and analysis tools, respectively, Volko Straub for help with the laser setup, and Jan Ache for valuable comments on this manuscript.

This article is freely available online through the J Neurosci Author Open Choice option.

Correspondence should be addressed to Tom Matheson, University of Leicester, Department of Biology, University Road, Leicester LE1 7RH, UK. E-mail: tm75@le.ac.uk.

D. Calas-List's present address: Laboratory of Receptor and Membrane lon Channels, Unit of Training and Research Sciences, University of Angers, 2 Boulevard Lavoisier, F-49045 Angers, France.

DOI:10.1523/JNEUROSCI.2200-13.2014

Copyright $\odot 2014$ Calas-List et al.

This is an Open Access article distributed under the terms of the Creative Commons Attribution License (http://creativecommons.org/licenses/by/3.0), which permits unrestricted use, distribution and reproduction in any medium provided that the original work is properly attributed. rate movements, humans prefer a speed modulation strategy to a co-contraction strategy (i.e., they use slower movements, not stiffer ones; Missenard and Fernandez, 2011).

Insects also make aimed limb movements. For example, locusts respond to tactile stimuli (Page and Matheson, 2004) with limb movements that are aimed at the site of stimulation. The accuracy of these movements and the patterns of excitatory motor activity underlying them were well described previously (Berkowitz and Laurent, 1996a,b; Matheson, 1997, 1998; Durr and Matheson, 2003; Matheson and Dürr, 2003; Zakotnik et al., 2006), making them a suitable system in which to analyze speed/ accuracy tradeoffs. Proprioceptive signals are required for accurate aiming (Page and Matheson, 2009), and co-contraction of antagonist muscles together with high levels of passive forces at the femur-tibia ("knee") joint can enhance load compensation (Zakotnik et al., 2006), but it is not known whether these elements of joint stiffness contribute to regulation of either accuracy or speed.

In arthropods, muscle contraction and relaxation dynamics, and thus joint stiffness, are influenced by inhibitory motor neurons that can either be specific to a particular muscle or innervate several muscles (Wiersma and Ripley, 1952; Pearson and Bergman, 1969; Pearson, 1973; Wolf, 1990). In the locust metathoracic ganglion, there are three such "common inhibitor" neurons $\left(\mathrm{CI}_{1}-\mathrm{CI}_{3}\right)$ innervating 17 hindleg muscles at four joints (Hale and Burrows, 1985). They innervate almost exclusively muscle fibers that are also innervated by slow excitatory motor neurons. Common inhibitors presynaptically inhibit the slow excitatory motor 
neurons (Rathmayer and Erxleben, 1983) and cause inhibitory junctional potentials in the slow muscle fibers (Usherwood and Grundfest, 1964). They act to reduce relaxation times (Usherwood and Runion, 1970) and reduce the force generated by an excitatory motor signal (Pearson, 1973), thus facilitating fast cyclical leg movements (Pearson, 1973; Wolf, 1990).

We hypothesized that changes in muscle properties brought about by the action of $\mathrm{CI}_{1}$, which innervates many muscles of a locust leg, should influence both the velocity and accuracy of aimed movements. We characterized the activity of $\mathrm{CI}_{1}$ during unconstrained aimed movements and then manipulated this activity to determine its influence. We demonstrate that common inhibition provides a mechanism by which insects can regulate the velocity of an aimed movement without compromising accuracy. We suggest that joint stiffness arising from high passive joint forces at the extremes of movement ranges constrains limb trajectories, whereas joint stiffness governed by muscle properties constrains movement velocities.

\section{Materials and Methods}

Experiments were performed on adult female desert locusts, Schistocerca gregaria (Forskål), $\sim 1$ week after the imaginal moult. Insects were reared in a crowded colony, kept in a temperature-controlled room $\left(36^{\circ} \mathrm{C}\right.$ day, $25^{\circ} \mathrm{C}$ night) under a $12 \mathrm{~h}$ light/dark cycle. Experiments were performed at $25^{\circ} \mathrm{C}$.

Insect preparation and stimulation protocol. Locusts were fixed ventral side up with beeswax on a 1-cm-diameter metal rod. To permit stabilization of the thorax and ganglia for long-term intracellular recordings, all the legs except the left hindleg were amputated at the coxa, and the stumps were sealed with beeswax. The tarsus of the left hindleg was allowed to rest on a horizontal platform located $24 \mathrm{~mm}$ posterior and 2 $\mathrm{mm}$ ventral (in animal-centered coordinates) to the metathoracic coxal joint. This provided a consistent start position before each leg movement. The animal was free to move its leg. The eyes were covered with black acrylic paint (Cryla; Daler-Rowney). Retroreflective circular markers (Scotchlite; $3 \mathrm{M}$ ) of $1.5 \mathrm{~mm}$ diameter were fixed to specific locations on the hindleg, thorax, and wing using clear nail varnish (Zakotnik et al., 2004, 2006; Page et al., 2008). These provided high-contrast reference points for subsequent video-based motion detection. Scratching movements were elicited by applying light stimulation using a fine paintbrush to either an anterior or a posterior location on the left (ipsilateral) forewing (Durr and Matheson, 2003; Page et al., 2008). Anterior and posterior stimulations were applied in random order. The accuracy of the stimulation is indicated in Figure 8.

The structure, musculature, and innervation of the locust hindleg were reviewed by Burrows (1996). In brief, the limb consists of the following (from proximal to distal): a coxal segment, a trochanter that is fused to the femur, a tibia, three tarsal segments, and an unguis. The thoracocoxal and coxo-trochanteral joints together act as the "hip," providing a wide range of movements (protraction-retraction, levation-depression, and rotation) of the entire limb. These movements are controlled by $\sim 17$ muscles. The femoro-tibial ("knee") joint is a hinge that allows extensions and flexions of the tibia through an arc of $\sim 160^{\circ}$ relative to the femur. The tibia is acted on directly by just two muscles: the extensor tibiae and the flexor tibiae. The tarsal segments and unguis together make up the foot, which is not considered further here.

Electromyogram recordings. Patterns of extensor and flexor tibiae muscle activity were recorded using two electromyogram (EMG) electrodes made from pairs of $25-\mu \mathrm{m}$-diameter polyester-insulated copper wires (Advent Research Materials). The tips of the wires were stripped of their insulation and inserted through the cuticle into proximal flexor tibiae muscle bundles a1-a3 (Sasaki and Burrows, 1998) and into the most distal bundle of the main extensor tibiae muscle (Hoyle, 1978; Zakotnik et al., 2006; Page et al., 2008). The metathoracic flexor tibiae muscle is innervated by nine excitatory motor neurons, each of which innervates a known restricted array of muscle bundles (Sasaki and Burrows, 1998). These neurons can be classified further into three classes (slow, fast, and intermediate) according to the movements that they cause, their firing patterns, thresholds, and evoked excitatory junctional potential amplitudes (Sasaki and Burrows, 1998). We recorded the activity of fast, slow, and intermediate flexor tibiae motor neurons $1,3,4-7$, and 9 , identified according to the patterns of innervation described by Sasaki and Burrows (1998). Slow and intermediate motor neuron spikes were treated as a single pool. They had small-amplitude spikes and were tonically active, whereas the fast motor neurons produced individual spikes or brief bursts. Fast motor neurons generally have the largest amplitude spikes visible in myogram recordings from locust leg muscles (Pearson and Robertson, 1981; Ryckebusch and Laurent, 1993; Sasaki and Burrows, 1998). The flexor tibiae muscle is also innervated by two common inhibitory motor neurons $\left(\mathrm{CI}_{2}\right.$ and $\left.\mathrm{CI}_{3}\right)$ and by the dorsal unpaired median neuron with axon branches in nerves 3 , 4 , and $5\left(\mathrm{DUM}_{3,4,5}\right)$, but the activity of these neurons is not visible in EMGs and we do not consider them further here.

The metathoracic extensor tibiae muscle is innervated by only four motor neurons: the fast (FETi) and slow (SETi) excitatory extensor tibiae neurons, common inhibitor $\mathrm{CI}_{1}$ (Hoyle, 1955a,b), and the dorsal unpaired median neuron to the extensor tibiae (Hoyle, 1978). Our extensor tibiae myogram recorded the activity of FETi and SETi, which can be unambiguously identified using spike shape and amplitudes, resistance reflex responses to imposed movements of the tibia, and correlation of activity with spontaneous movements (Page et al., 2008). FETi spikes were also characterized by their consistent crosstalk onto the flexor EMG. All EMG recordings were inspected by eye, and the few movement artifacts were omitted before detailed analyses.

Intracellular and extracellular neuronal recordings. To obtain intracellular recordings from the soma of $\mathrm{CI}_{1}$ and extracellular recordings from the leg nerves, a window was cut through the ventral cuticle of the thorax to expose the metathoracic ganglion and its lateral nerves on the left side. The ganglion was exposed by displacing and partially removing tracheal air sacs, leaving intact the main tracheal supply to the ganglion itself. The ganglion was then stabilized with minutien pins on a wax-covered silver platform, and its sheath was treated with protease (type XIV; Sigma) for $30 \mathrm{~s}$ before recording. Standard locust saline solution (Usherwood and Grundfest, 1965) was used to rinse off the protease and was added throughout the experiment as necessary.

The soma of $\mathrm{CI}_{1}(\sim 65 \mu \mathrm{m}$ diameter $)$ was impaled with a glass microelectrode filled with $2 \mathrm{M}$ potassium acetate and that had a tip resistance of $90-130 \mathrm{M} \Omega$. The cell was identified by the location of its cell body near the midline of the ganglion and by a 1:1 correlation between its spikes recorded intracellularly and from its axon in leg nerve N5A. There is no central electrical or chemical coupling between $\mathrm{CI}_{1}, \mathrm{CI}_{2}$, or $\mathrm{CI}_{3}$. Nerve $\mathrm{N} 5 \mathrm{~A}$ was recorded en passant with bipolar hook electrodes made from a pair of $75-\mu \mathrm{m}$-diameter Teflon-insulated silver wires. It contains only four axons: those of two excitatory motor neurons, the fast (Df) and the slow (Ds) depressor of the trochanter, that of a neuromodulatory dorsal unpaired median neuron $\left(\mathrm{DUM}_{3,4,5}\right)$, and that of $\mathrm{CI}_{1}$ (Braunig, 1997; Braunig and Eder, 1998). Spikes of Df were always the largest in our recordings and were easily identifiable by their size and phasic pattern of activity. Spikes of Ds were the next largest and were again easily identifiable by their size and generally tonic pattern of activity. Spikes of $\mathrm{CI}_{1}$ were smaller again and were identified by their 1:1 correlation with spikes recorded intracellularly from the soma of $\mathrm{CI}_{1}$. Spikes of $\mathrm{DUM}_{3,4,5}$ were generally the smallest in our recordings and had a waveform different from those of $\mathrm{CI}_{1}$. They were identified by first assigning all other spikes to $\mathrm{Df}, \mathrm{Ds}$, or $\mathrm{CI}_{1}$. In some experiments, the activity of $\mathrm{CI}_{1}$ was manipulated by injecting hyperpolarizing ( -1 to $-4 \mathrm{nA}$ ) or depolarizing (1-4 $\mathrm{nA}$ ) currents into its soma. Injected current was monitored using the intracellular amplifier, but the exact pattern of spread of current from the passive soma to the spike initiating zone of $\mathrm{CI}_{1}$ is unknown.

Extracellular recordings were amplified $(1000 \times)$ and filtered using a differential alternating current amplifier (model 1700; A-M Systems). EMG recordings were filtered using a $50 \mathrm{~Hz}$ notch and $100 \mathrm{~Hz}$ to $1 \mathrm{kHz}$ bandpass filters. Nerve 5 recordings were filtered with a $50 \mathrm{~Hz}$ notch filter and $10 \mathrm{~Hz}$ to $10 \mathrm{kHz}$ bandpass filters. Intracellular signals were amplified and filtered using an Axoclamp 900A amplifier (Molecular Devices; direct current, $10 \mathrm{kHz}$ bandpass filter). Data were recorded and stored on a 
computer using a Cambridge Electronic Design micro1401 interface and Spike2 software version 6 (Cambridge Electronic Design). Spike2 files were cut to extract individual scratches using custom software (EMGcalc; J. Zakotnik, University of Bielefeld, Bielefeld, Germany). Spikes were detected using a combination of adjustable thresholds (Spike2) and manual identification in a custom program (Locustbrowse; A.J.C.).

Photoablation of $\mathrm{CI}_{1}$. In 10 animals, $\mathrm{CI}_{1}$ was inactivated (killed) using laser photoablation (Miller and Selverston, 1979; Bässler and Rathmayer, 1996; Büschges et al., 2000). Animals were prepared as described above, but microelectrode tips were filled with $4 \%$ 5(6)-carboxyfluorescein (Sigma) in $1 \mathrm{M} \mathrm{KCl}$, and their shafts were filled with $1 \mathrm{~m} \mathrm{KCl}$. These electrodes had tip resistances of $80-120 \mathrm{M} \Omega$. EMG recordings were not made in these animals. After penetration of $\mathrm{CI}_{1}$, a series of aimed scratches was recorded, and then $\mathrm{CI}_{1}$ was filled with dye by injection of hyperpolarizing current ( $-5 \mathrm{nA}$ for $\sim 8 \mathrm{~min}$ ). After $15 \mathrm{~min}$ diffusion, the dye-filled cell was killed by illuminating the ganglion with a $9 \mathrm{~mW}$ beam of blue light emitted from a Photop Technologies Diode Pump Solid State laser (model DPBL-9010, $473 \mathrm{~nm}$; Sp3plus) driven by a Photop Technologies LDC-2500S power supply (Sp3plus) and custom-built controller (Joint Biomedical Workshops, University of Leicester). The laser beam was focused (100 $\mu \mathrm{m}$ spot diameter) onto the soma of $\mathrm{CI}_{1}$ using an optical fiber light guide (OzOptics) and filter (Brightline FF01514/30-25; Laser 2000) from a distance of $65 \mathrm{~mm}$ for 10-15 min. Cell death was confirmed by monitoring the soma depolarization, spiking damage discharge, and subsequent inactivity of $\mathrm{CI}_{1}$ in the intracellular soma recording and in the peripheral N5A recording. After cell death, additional scratches were elicited while electrophysiological recordings were maintained to confirm a lack of activity in $\mathrm{CI}_{1}$. In total, 152 scratches before and 221 scratches after photoablation were analyzed from 10 animals (animals different from those used for experiments in which $\mathrm{CI}_{1}$ was manipulated by current injection).

Video acquisition. Locusts were videotaped from the left side using a color video camera (TK-C1380; JVC) with a Tamron $28 \mathrm{~mm}$ lens and a $0.002 \mathrm{~s}$ shutter speed. To illuminate the reflective markers, an optical fiber light (KL-1500 LCD; Schott) was arranged so that its light beam was aligned close to and parallel with the axis of the camera lens. The video images were time-stamped using a video timer (VTG-33; FOR-A), recorded on a sVHS video recorder (HR-S7500EK; JVC), and displayed on a monitor (PVM-1450MD; Sony). Interlaced PAL video frames were captured offline at a size of $720 \times 576$ pixels using a computer video interface card (miroVIDEO DC30 plus; Pinnacle Systems) with DVTools software (Pinnacle Systems). The .AVI files were then deinterlaced (to give 50 frames/s) and subsequently edited using VirtualDub (http://www.virtualdub.org/index) to produce video clips of individual scratches. A custom-written program (Videotrack 2D; J. Zakotnik) was used to detect the retroreflective markers and provide their coordinates. A light-emitting diode (LED) placed in the field of view was manually triggered to flash before and after each scratch to permit synchronization of the videotaped movements with the electrophysiological activity. The LED triggering pulse was recorded together with the electrophysiological signals to give a temporal accuracy of $\pm 10 \mathrm{~ms}$ (interframe interval, 20 $\mathrm{ms}$ ). A total of 245 scratches were filmed and analyzed from six animals in which we made simultaneous EMG, nerve, and intracellular recordings.

Comparison of upright and upside-down animals. Locusts were tethered around the pronotum using a loop of thin wire, which held the animal at normal walking height above an expanded polystyrene ball $(6 \mathrm{~cm}$ diameter) in an upright or upside-down position. The eyes were covered with black acrylic paint, and retroreflective circular markers were placed on the body. The left mesothoracic leg was amputated to prevent it occluding the body markers, and the tarsus of the left hindleg was placed on a horizontal rod held in a fixed position relative to the animal as described above.

Scratching movements were filmed and analyzed as described above. Scratches were categorized as "anterior" if the stimulus site was in the anterior $40 \%$ of the wing and as "posterior" if the stimulus site was in the posterior $40 \%$ of the wing (Durr and Matheson, 2003). A total of 242 scratches were recorded and analyzed from six animals [10 scratches for each combination of orientation (upright and upside down) and stimu- lus site (anterior and posterior)]. These were different animals from those used for the electrophysiological analyses.

Data analysis. Movement variables were computed from the videotracked data using custom software as described in detail previously [ScratchAnalysis (Durr and Matheson, 2003)]. Limb joint angles are defined as in the study by Page et al. (2008). Briefly, for the thoraco-coxal and coxo-trochanteral joints, larger angles correspond to levation and smaller angles to depression. For the femoro-tibial joint, larger angles correspond to extension and smaller angles to flexion. The natural limits of movement of the femoro-tibial joint mean that it lies at $\sim 10^{\circ}$ when the tibia is fully flexed against the femur. It cannot extend past $\sim 170^{\circ}$.

Scratches consist of rhythmic tibial extensions and flexions driven by alternating extensor and flexor tibiae muscle activity and by passive forces intrinsic to the muscles and joints (Page et al., 2008; Ache and Matheson, 2013). Tibial motor neurons could produce either individual spikes or burst of spikes (Page et al., 2008). We defined SETi bursts as consisting of a group of action potentials with a maximum interspike interval of $25 \mathrm{~ms}$. We defined flexor tibiae bursts as consisting of a group of action potentials with a maximum interspike interval of $30 \mathrm{~ms}$. These values were determined by trial and error in preliminary analyses to give the most reliable separation of bursts. Scratches are composed of an initial outward trajectory (200 ms; Durr and Matheson, 2003) and usually a subsequent cyclical component. The cyclical component was analyzed using probability distributions describing the likelihood with which the distal part of the tibia moved across each point in the workspace of the limb. In brief, the $100 \times 100 \mathrm{~mm}$ workspace within which the hindlimb moved was subdivided into a $1 \mathrm{~mm}$ lattice. For each scratch, we determined the number of observations (video frames) in which the distal tibia was observed at each point in the lattice. The resulting twodimensional (2D) frequency histograms were spatially smoothed using a 2D Gaussian filter of $5 \times 5 \mathrm{~mm}$ area and $\sigma=2 \times 2 \mathrm{~mm}^{2}$, normalized to a standard volume, and averaged across trials. The histograms were treated as empirical likelihood functions, and Bayes' rule was used to determine the critical number of frames needed to distinguish between pairs of distributions. If the critical number was smaller than the average number of video frames per scratch in the samples being compared, the two distributions were considered statistically different. We preserved the full range of natural variability in the behavior by basing the analyses on individual scratches (equal numbers recorded from each animal; for details, see Durr and Matheson, 2003). When comparing movement distributions in Results, we note their percentage overlap, the critical number of frames required to distinguish between them, the mean number of frames per scratch in the sample, and a statement of significance.

For each scratch, the point of closest approach of the distal tibia (the "effector point") to the stimulus site on the wing (target) was also computed, thus providing a single measure of accuracy for each movement. As described in detail by Durr and Matheson (2003), the effector point was defined as a point $4 \mathrm{~mm}$ from the distal end of the tibia for all movements. For posterior targets, in which the closest point reported by our analysis lies anterior to the target (see Fig. 8; Durr and Matheson, 2003, their Fig. $3 A$, target 5 ), the tarsus is frequently closer (simply because of limb geometry, with the foot pointing posteriorly). For anterior targets in which the reported closest point is most often posterior to the target, more proximal locations on the tibia are frequently closer (Durr and Matheson, 2003, their Fig. 3A, target 2). To make meaningful comparisons across treatments, we consider the same effector point in all cases, but this necessarily underestimates accuracy.

The reference point in all movement analyses was the anterior edge of the metathoracic coxal rim. Locations posterior or ventral to this had negative $x$-coordinate or $y$-coordinate values, respectively. For experiments on upright and upside-down locusts, limb movement velocities were also computed for the initial outward trajectory $(0-200 \mathrm{~ms})$ and the cyclical components of each scratch. Our use of two spatial descriptors [probability density distributions describing the overall form and point of closest approach characterizing functional accuracy (Durr and Matheson, 2003)] contributes to the suitability of this system for assessing the tradeoff between speed and accuracy.

Hindleg joint angle data were synchronized with the simultaneously recorded intracellular and extracellular signals offline using custom- 
A

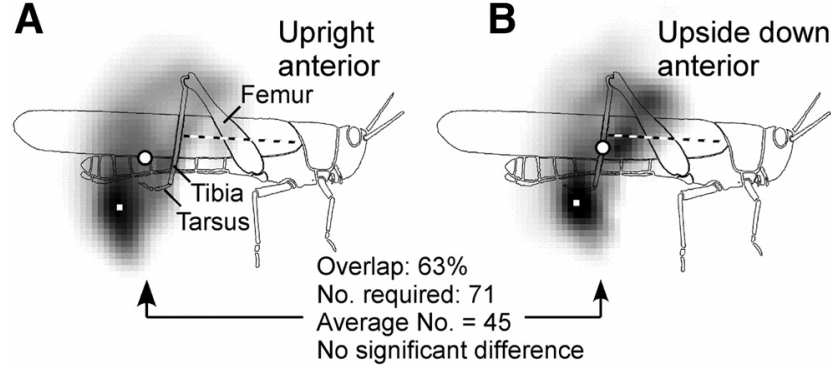

C

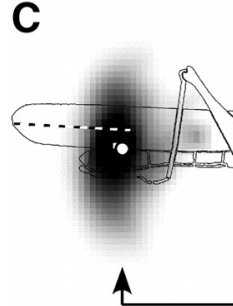

Upright posterior

$\overline{10 \mathrm{~mm}}$

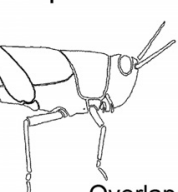

Overlap: $81 \%$

No. required: $>500$

Average No. $=61$

No significant difference
D

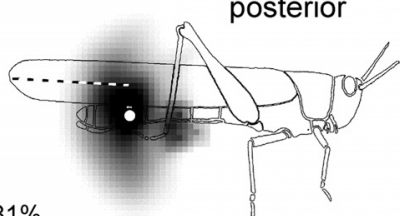

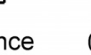

Figure 1. Orientation had no effect on the area crossed by the distal end of the tibia during scratching. Shading represents the probability distributions for movements aimed at anterior $(\boldsymbol{A}, \boldsymbol{B})$ and posterior $(\boldsymbol{C}, \boldsymbol{D})$ target sites for upright and upside-down locusts. All locusts are illustrated upright to ease comparisons. The femur, tibia, and tarsus of the hindleg are indicated. The grayscale codes for probability density between 0 (white) and 0.004 (black) at $1 \mathrm{~mm}$ spatial resolution (see grayscale calibration bar). White circles, The center of density; white squares, the point of maximum density. Black and white dashed lines indicates the region of wing stimulated. "Overlap" indicates the percentage volume overlap of the two distributions. Two distributions are considered to differ significantly $(p<0.05)$ if the number of frames required ( $N$ o. required) to distinguish them is smaller than the average number of frames (Average No.) of the observed scratches (i.e., the mean response duration in frames). $n>10$ scratches for each condition for each of 6 animals.

written software (Locustbrowse; A.J.C.). Data analyses were performed using Locustbrowse for different time periods of each movement: (1) premovement; (2) during the first cycle; and (3) during the whole scratch.

Patterns of activity in the excitatory and inhibitory motor neurons to the extensor and flexor tibiae muscles were analyzed using a customwritten cross-correlation procedure that was required to deal with the relatively short durations of scratches $(2 \pm 1 \mathrm{~s})$ relative to the $0.4 \mathrm{~s}$ cross-correlation analysis window. To compute the cross-correlation for a pair of simultaneously recorded spike trains, we created a frequency histogram of the time differences between all combinations of spike events in the two recordings for the first scratch. We then built up this histogram by adding corresponding data from each subsequent scratch from the same animal. This produced triangular cross-correlation plots with peaks at $0 \mathrm{~s}$ because scratch durations were relatively short compared with the analysis window. We confirmed that this was the case by building up similar cross-correlation histograms for pairs of simulated spike trains with independent Poisson-distributed spike times (and thus no cross-correlation). This underlying pattern was removed from the analysis of real data as follows. For every pair of real spike trains, we also calculated cross-correlation plots for Poisson-distributed spike trains simulated with mean rates and scratch durations identical to those of the real data. We then subtracted these simulated cross-correlations from the cross-correlations computed from the real data after normalizing both simulated and observed cross-correlations to unit area. Therefore, this procedure yields a measure of fractional change in cross-correlation that is not attributable to Poisson randomness. Cross-correlations were computed independently for six animals, with the number of spikes per animal varying (from minimum to maximum): $\mathrm{CI}_{1}, 507-$ 3025; SETi, 757-3358; FETi, 42-152; and flexors, 878-3101.

Statistical tests. Values are reported as mean \pm SD unless stated otherwise. Means were compared using $t$ tests or, when the data failed the Shapiro-Wilk normality test, Mann-Whitney rank-sum tests (Sigma-

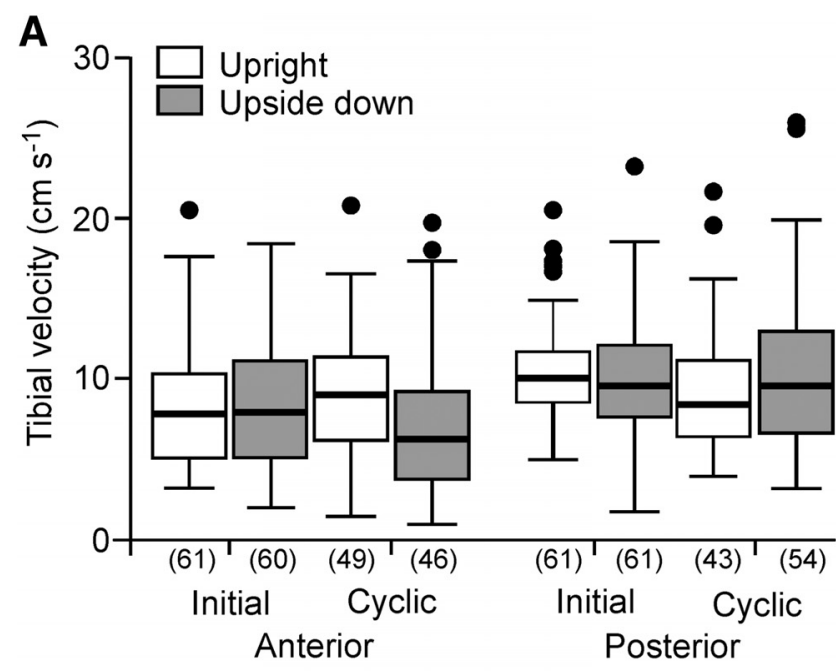

B
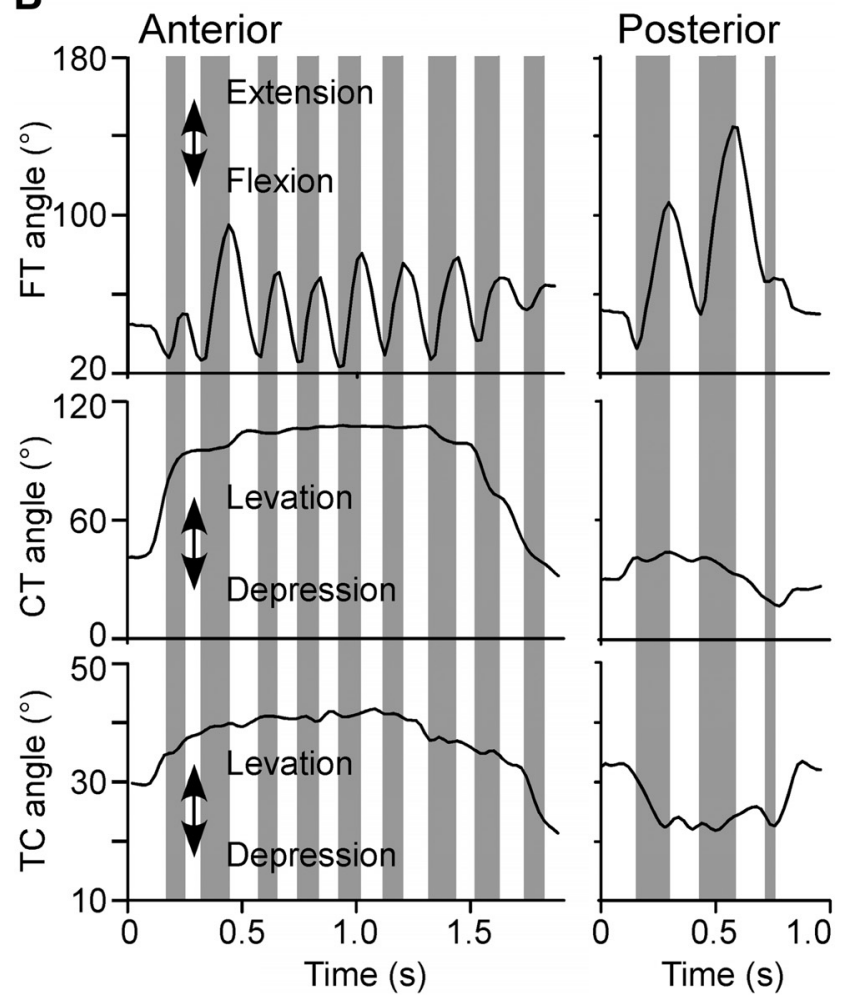

Figure 2. A, Orientation had no effect on tibial movement velocity for either the initial 200 ms of movement (Initial) or the cyclic part of the scratch (Cyclic). In all cases, the median velocity (thick horizontal lines) for scratches in upside-down locusts fell within the interquartile range (boxes) for scratches elicited in upright locusts, and the ranges overlapped almost completely (95\% of values lie within the whiskers, outliers are shown as black dots). This was the case for scratches elicited by anterior stimulation (left side of figure) and for those elicited by posterior stimulation (right side of figure). The number of scratches is indicated in parentheses. $\boldsymbol{B}$, Anterior and posterior scratches were cyclical movements driven by the coordinated action of three limb joints. Graphs show time courses of joint angular change for the femoro-tibial (FT; top), coxo-trochanteral (CT; middle), and thoraco-coxal (TC; bottom) joints, for a scratch aimed at an anterior stimulus (3 left panels) and scratch aimed at a posterior stimulus (3 right panels). Gray shading marks tibial extension.

Plot version 11.0). A one-way ANOVA was used to analyze the "closest point" data. When the data failed a Shapiro-Wilk normality test, a Kruskal-Wallis one-way ANOVA on ranks was used instead. The significance values of linear regressions for the femoro-tibial joint velocity data were calculated using ANOVA (SigmaPlot version 11.0). Joint velocities 


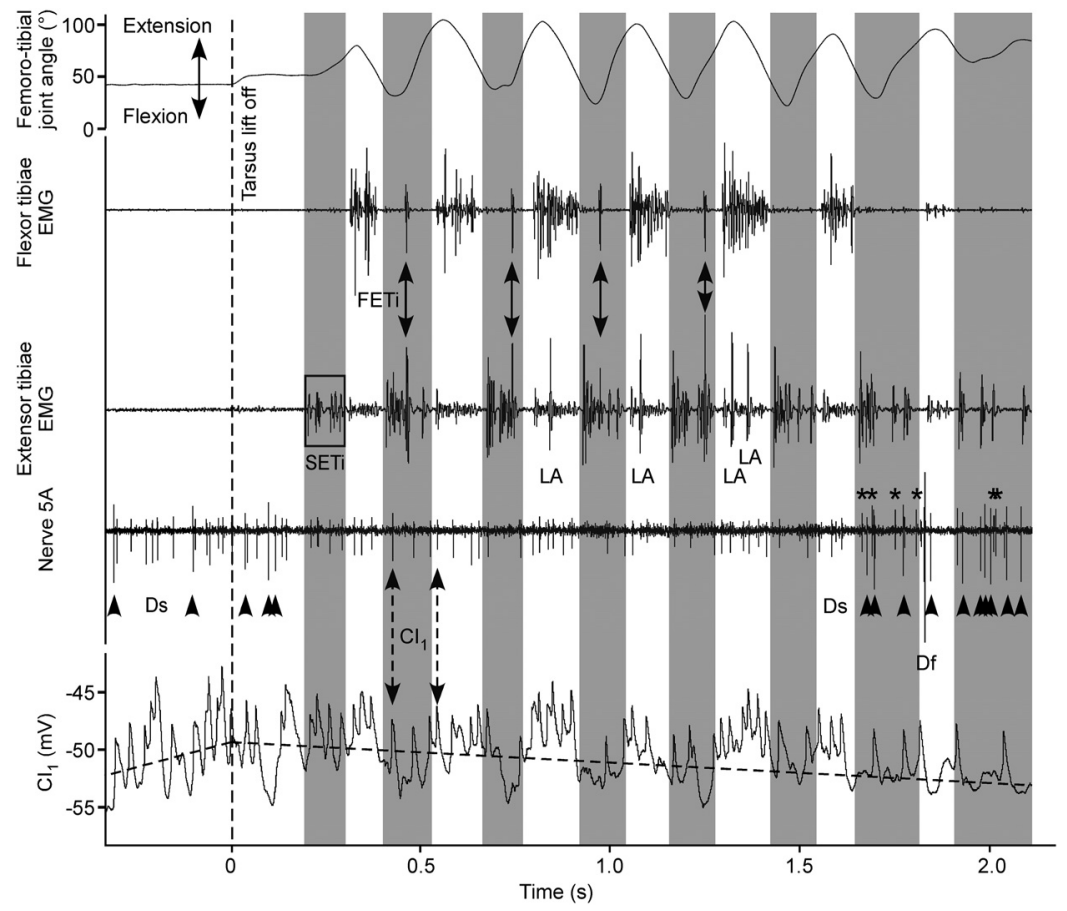

Figure 3. $\mathrm{Cl}_{1}$ activity preceded tibial movement and was modulated in the scratch rhythm. Traces from top to bottom recorded simultaneously during an anterior scratch: femoro-tibial joint angle, EMG recording from flexor tibiae muscle, EMG recording from extensor tibiae muscle, extracellular recording of nerve $\mathrm{N} 5 \mathrm{~A}$, and intracellular recording from the soma of $\mathrm{Cl}_{1}$. Gray shading marks bursts of extensor tibiae motor activity. SETi (e.g., box, trace 3) fired several spikes on each cycle of movement, whereas FETi (filled double-headed arrows) fired only one spike on some cycles. FETi spikes were identified by their characteristic crosstalk onto the flexor channel (trace 2). In this recording, some flexor crosstalk was evident in the extensor channel. Large-amplitude flexor tibiae motor spikes apparent in this crosstalk are identified by LA (trace 3). In this example, the trochanteral fast depressor motor neuron was silent but for one spike (Df; trace 4). Ds was tonically active before movement onset, but this activity ceased (last 5 spikes marked with arrowheads) soon after the tarsus lifted off the start platform (vertical dashed line) and restarted toward the end of the scratch (arrowheads). Asterisks mark six spikes of a dorsal unpaired median neuron (DUM $\left.{ }_{3,4,5}\right)$ visible in the nerve N5A recording. $\mathrm{Cl}_{1}$ was active at the start of the scratch (spikes are visible in the bottom 2 traces, e.g., dashed arrows) and spiked throughout the movement. The membrane potential recorded in the soma depolarized before tarsal liftoff and then repolarized gradually during the movement (sloping dashed lines), and this was accompanied by an overall reduction in spiking rate. Transient hyperpolarizations and depolarizations in time with the scratching rhythm were superimposed on this overall trend (bottom trace), leading to rhythmical fluctuations in $\mathrm{Cl}_{1}$ firing rate.

were compared using Mann-Whitney rank-sum tests with Holm-Bonferroni correction for repeated testing. $N$ indicates the number of animals, and $n$ indicates the number of scratches. The majority of our analyses are based on data from six animals that each made a number of movements aimed at randomly interleaved anterior or posterior targets, at intervals of $\geq 1$ min over several hours. Between recorded trials, the animals often moved their intact hindlimb and remaining limb stumps in response to tactile stimuli applied randomly to the wings, body, and head. The hindlimb was also manually repositioned onto the start platform before each recorded movement, which frequently took several separate manipulations. In experiments in which the membrane potential of $\mathrm{CI}_{1}$ was manipulated, current injections were applied in blocks of differing intensity repeated randomly as scratches were elicited as described above. Given this experimental design with disrupting/arousing stimuli applied between trials and a resetting of the start location, along with the need to relate, for example, the firing rate of $\mathrm{CI}_{1}$ during a specific trial to movement variables during the same trial, we based our figures and analyses on individual trials that we treat as independent. When appropriate, we also show data separated by animal.

\section{Results}

\section{Upside-down locusts scratch normally}

Intracellular recordings from the soma of $\mathrm{CI}_{1}$ are most conveniently made from animals fixed ventral side up. In an initial series of experiments, we demonstrated that upside-down animals scratched in the same way as upright animals (Fig. 1; Durr and Matheson, 2003). In both upright and upside-down locusts, gentle tactile stimulation of a front wing elicited scratching movements of the ipsilateral hindleg. Probability distributions for movements of the distal tibia aimed at the same target region (anterior, Fig. $1 A$ vs $B$; or posterior, Fig. $1 C$ vs $D$ ) did not differ significantly $(p>0.05, n>10$ scratches for each condition for each of 6 animals; see Materials and Methods) in upright and upside-down animals, indicating that orientation had no effect on the overall area crossed by the distal tibia during the cyclic part of scratching movements. Movements aimed at anterior targets differed significantly $(p<0.05$; see Materials and Methods) from those aimed at posterior targets (overlap, 56\%; number of frames required, 35; average number, 53; upright and upside down data pooled, $n=242$ scratches in 6 animals). Animal orientation had no effect on the speed of movement of the distal tibia during either the initial outward movement or the cyclic part of a scratch (Fig. $2 A$, all medians within the contrasting interquartile range).

\section{Rhythmic scratching is driven by movements at three joints}

In upside-down locusts prepared for intracellular and EMG recording, scratching responses to tactile stimulation of the ipsilateral forewing were composed of 1-11 cycles. Our analyses were restricted to the first three cycles. The average duration of the first cycle was $0.63 \mathrm{~s}(0.6 \pm 0.59 \mathrm{~s}$ for anterior and $0.65 \pm 0.48 \mathrm{~s}$ for posterior scratches, $N=6, n=32$ and 55, respectively). The cyclical movements were generated by coordinated movements of the thoraco-coxal, coxo-trochanteral, and femoro-tibial joints. Scratches generally began with a brief femoro-tibial joint flexion, followed by a femoro-tibial joint extension (Fig. 2B, top). Movements aimed at anterior stimuli were underpinned by overall levation of the coxo-trochanteral and thoraco-coxal joints, whereas movements aimed at posterior stimuli showed a small amplitude levation of the coxotrochanteral joint but a depression of the thoraco-coxal joint (Fig. 2B, middle and bottom, contrast left and right). There were often small oscillations of the coxo-trochanteral and thoracocoxal joints during the scratch, but these were not necessarily tightly coupled to the more pronounced oscillations of the femoro-tibial joint (Fig. 2B). During posterior scratches, the femoro-tibial joint extended to a significantly greater mean angle than it did during anterior scratches (posterior, $71 \pm 17^{\circ}$; anterior, $53.6 \pm 15.7^{\circ} ; t$ test, $\left.t=4.71, \mathrm{df}=85, p=1 \times 10^{-6}\right)$. The maximum (extended) femoro-tibial joint angle was also greater for posterior movements (posterior, $117.3 \pm 20.12^{\circ}$; anterior, $93.7 \pm 18.8^{\circ} ; t$ test, $\left.t=5.398, \mathrm{df}=85, p<0.001\right)$. In contrast, the minimum (flexed) femoro-tibial joint angle for posterior and 
Table 1. Comparison of mean motor neuronal firing rates for scratches aimed at anterior and posterior target sites

\begin{tabular}{|c|c|c|c|c|c|c|c|c|c|c|c|c|}
\hline & \multicolumn{3}{|l|}{$\mathrm{Cl}_{1}$} & \multicolumn{3}{|l|}{ SETi } & \multicolumn{3}{|l|}{ FETi } & \multicolumn{3}{|l|}{ Flexors } \\
\hline & Anterior & Posterior & Both & Anterior & Posterior & Both & Anterior & Posterior & Both & Anterior & Posterior & Both \\
\hline Premovement & $34 \pm 18$ & $18 \pm 10^{a}$ & $24 \pm 16$ & $4 \pm 6$ & $20 \pm 17^{c}$ & $14 \pm 16$ & 0 & $0.8 \pm 2.8$ & $0.5 \pm 2.3$ & $8 \pm 13$ & $12 \pm 16$ & $10 \pm 15$ \\
\hline First cycle & $23 \pm 9$ & $16 \pm 8^{b}$ & $19 \pm 9$ & $36 \pm 19$ & $30 \pm 15$ & $32 \pm 17$ & $6.8 \pm 3.3$ & $6.5 \pm 3.5$ & $6.6 \pm 3.4$ & $39 \pm 24$ & $36 \pm 21$ & $37 \pm 22$ \\
\hline Whole scratch & $13 \pm 6$ & $12 \pm 6$ & $13 \pm 6$ & $30 \pm 15$ & $27 \pm 13$ & $28 \pm 14$ & $1.3 \pm 1.9$ & $2.2 \pm 2.3$ & $1.9 \pm 2.2$ & $28 \pm 16$ & $31 \pm 18$ & $29 \pm 17$ \\
\hline
\end{tabular}

Values are mean \pm SD spike rate (spikes per second) for $100 \mathrm{~ms}$ before the foot lifted off from the platform (Premovement), for the outward trajectory and first cyclical component (First cycle), and from tarsus liftoff until the end of the scratch (Whole scratch). Rates are shown separately for anterior $(n=32)$ and posterior $(n=55)$ scratches and are also pooled (Both). Comparisons between anterior and posterior target sites: ${ }^{a} t$ test, $\mathrm{df}=85, p<0.001$; ${ }^{\mathrm{b}} \mathrm{Mann}-\mathrm{Whitney}$ rank-sum test, $U=379.5, p<0.001$; 'Mann-Whitney rank-sum test, $U=321.5, p<0.001$.

anterior scratches was very similar (posterior, $36.39 \pm 13.8^{\circ}$; anterior, $29.34 \pm 16.30^{\circ}$; Mann-Whitney rank-sum test, $U=691$, $p=0.097)$.

\section{$\mathrm{CI}_{1}$ is active during scratching}

In quiescent locusts, $\mathrm{CI}_{1}$ was generally silent or fired occasionally. The average resting membrane potential was $-49 \pm 8 \mathrm{mV}(\mathrm{N}=$ 16). During scratching movements consisting of alternating tibial extensions and flexions, $\mathrm{CI}_{1}$ depolarized by $\sim 5 \mathrm{mV}$ and fired rhythmically in time with the movements (Fig. 3). Action potentials recorded intracellularly from the primarily passive soma of $\mathrm{CI}_{1}$ had amplitudes of $5.5 \pm 2.6 \mathrm{mV}(n=16$; Fig. 3$)$ and were stable throughout all analyzed recordings. $\mathrm{CI}_{1}$ was active during all scratching movements with a mean firing rate of 13 spikes/s for the whole scratch (Table 1). This overall firing rate was the same in anterior movements (13 \pm 6 spikes/s) and posterior movements ( $12 \pm 6$ spikes/s; Mann-Whitney rank-sum test, $U=$ $793, p=0.446)$. The firing rate during a $100 \mathrm{~ms}$ premovement period before tarsal liftoff was 1.9-fold higher during anterior movements than posterior movements (34 vs 18 spikes/s). Similarly, the firing rate during the first cycle was 1.4-fold higher during anterior movements than posterior movements (23 vs 16 spikes/s; Table 1).

When a locust was touched on a forewing to elicit scratching, $\mathrm{CI}_{1}$ generally started firing before the excitatory SETi and FETi and before the flexor tibiae motor neurons. The firing rate of $\mathrm{CI}_{1}$ typically peaked as the tarsus (foot) lifted off from the substratum (Fig. 4, Table 1) and diminished during the course of a scratch (Fig. 3, Table 1). This overall trend was modulated in time with the scratch cycle (Fig. 3). $\mathrm{CI}_{1}$ fired at a higher rate during flexor tibiae motor neuron bursts than during SETi bursts $(21 \pm 8$ vs $13 \pm 4$ spikes/s, paired $t$ test, $\mathrm{df}=5, p=0.02 ; n=87$ scratches from 6 locusts). Because the activity of common inhibitory motor neurons is known to modify muscle properties that affect joint stiffness, these data suggest that locusts modulate joint stiffness during unconstrained aimed movements.

\section{Excitatory motor neuron activity during scratching}

In quiescent upside-down locusts that held their hind tarsus on the starting platform, Df was silent and Ds was tonically active. The tonic firing of Ds ceased at approximately the time of tarsal liftoff and restarted toward the end of the scratch, often accompanied by spikes in Df (Fig. 3). Some recordings from nerve N5A revealed additional smaller-amplitude action potentials (sometimes almost as large as those of $\mathrm{CI}_{1}$ but with a different shape). These are likely to be from the dorsal unpaired median neuron $\left(\mathrm{DUM}_{3,4,5}\right)$ that innervates muscle 133a in the thorax via nerve N5A (Braunig, 1997; Braunig and Eder, 1998). The patterns of activity in Df, Ds, and DUM $_{3,4,5}$ varied considerably between animals, and we do not consider them further here.

SETi firing rate during the premovement period was significantly higher for posterior (20 spikes/s) than anterior (4 spikes/s) movements (Table 1). This difference disappeared once the scratch movement began, with SETi firing at a rate of 28 spikes/s averaged across the entire movement (Table 1). Bursts of SETi spikes were generally associated with each tibial extension movement (Fig. 3).

FETi did not spike during the premovement period for scratches elicited by anterior stimuli but spiked occasionally $(\sim 1$ spikes/s) before posterior scratches (Fig. 4, Table 1). FETi fired at significantly higher rates $(\sim 7$ spikes/s) during the first cycle of a scratch than during the premovement period for both anterior $(p<0.001, U=16)$ and posterior $(p<0.001, U=196)$ targets. FETi contributed $0-13$ spikes per cycle (median of $1, n=87$ scratches in 6 animals). The firing rate during the first cycle was also higher than the rate averaged across the whole scratch $(\sim 2$ spikes/s; anterior, $p<0.001, U=84.5$; posterior, $p<0.001, U=$ 402.5). Nevertheless, the firing rate averaged across the whole scratch exceeded the firing rate during the premovement period (anterior, $p<0.001, U=208$; posterior, $p<0.001, U=599$ ). FETi spikes generally occurred during bursts of SETi spikes, but many cycles of movement did not include FETi activity (Fig. 3, last three cycles).

Flexor tibiae motor neurons were active during the premovement period for both anterior and posterior stimuli, with a mean firing rate of $\sim 10$ spikes/s (Figs. 3, 4, Table 1). The firing rate increased almost fourfold to 37 spikes/s during the first cycle of movement and remained high on subsequent cycles (mean rate for whole scratch, 29 spikes/s). Flexor spike rates were pooled across a variable number of flexor motor neurons in the EMG recording. During a scratch, bursts of flexor tibiae motor activity generally accompanied each tibial flexion (Fig. 3).

\section{Timing of excitatory and inhibitory motor activity}

During aimed scratches, the spiking activity of the excitatory motor neurons to the extensor and flexor tibiae muscles had well defined relationships to the activity of $\mathrm{CI}_{1}$ (Fig. 5). In all six animals, $\mathrm{CI}_{1}$ activity was negatively correlated with activity in SETi (Fig. $5 A$ and inset) and FETi (Fig. $5 B$ and inset) but positively correlated with activity in the flexor motor neurons (Fig. $5 C$ and inset). Activity of SETi was positively correlated with activity of FETi (Fig. 5D), whereas activity of both SETi and FETi was negatively correlated with the activity of flexor tibiae motor neurons (Fig. 5E,F).

\section{$\mathrm{CI}_{1}$ firing rate can be manipulated experimentally during natural scratching movements}

Depolarizing and hyperpolarizing currents injected into the soma of $\mathrm{CI}_{1}$ modulated the spontaneous firing rate of the cell during aimed scratching and permitted us to measure the consequences of $\mathrm{CI}_{1}$ action on limb movement. The mean firing rate under normal conditions (no current injection) was $13 \pm 6$ spikes/s. To compare $\mathrm{CI}_{1}$ firing rates after injection of depolarizing and hyperpolarizing currents, we expressed all firing rates as 


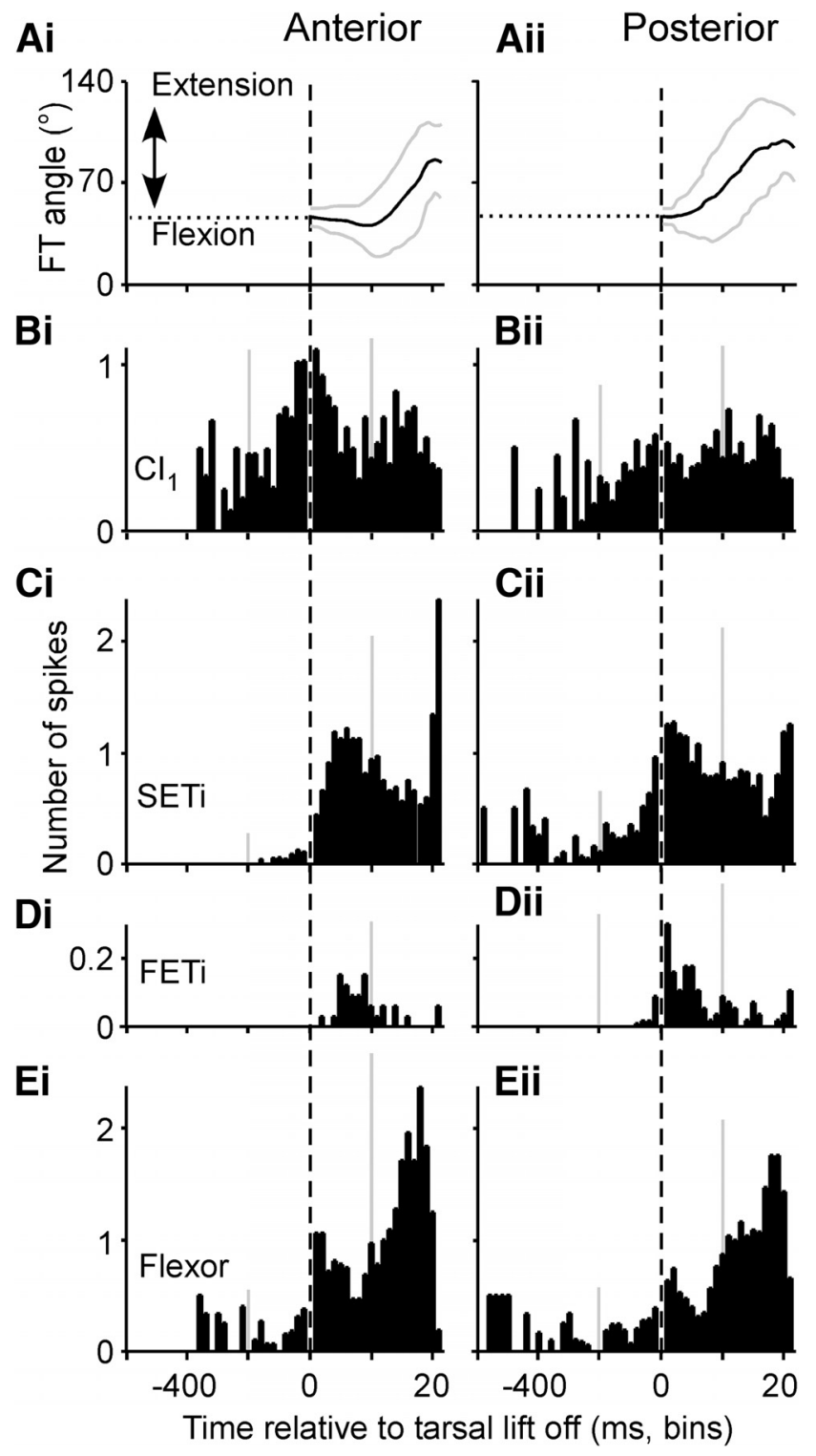

Figure 4. Patterns of motor activity differed for anterior (left column) and posterior (right column) scratches. Ai, Aii, The average pattern of femoro-tibial (FT) joint angular change from tarsal liftoff (vertical dashed lines) until the end of the first cycle of movement (solid lines, mean; gray lines, SD). The horizontal dotted lines indicate the joint angle during the premovement period. Histograms show the relative spike rates of $\mathrm{Cl}_{1}(\mathbf{B i}$, Bii), SETi (Ci, Cii), FETi (Di, Dii), and flexor (Ei, Eii) motor neurons for anterior and posterior scratching movements, before and during the first cycle. The premovement period (to the left of the vertical dashed lines) was divided into $20 \mathrm{~ms}$ bins. The first cycle of each scratch (to the right of the vertical dashed line) was standardized by dividing it into 20 bins of equal duration. The median (interquartile range) duration of the first cycles was 0.69 (0.35) for anterior and $1.0(0.71)$ for posterior scratches. Each histogram bar shows the number of motor spikes for one bin, averaged across $n=32$ anterior movements and 55 posterior movements. Vertical gray lines indicate representative (mean) SDs for pre-liftoff and post-liftoff periods in each histogram.

percentage change from the baseline condition in each animal. As shown above $\left(\mathrm{CI}_{1}\right.$ is active during scratching), $\mathrm{CI}_{1}$ firing rate is strongly modulated during active scratching movements. Injection of depolarizing current into $\mathrm{CI}_{1}$ during active scratching increased the overall firing of $\mathrm{CI}_{1}$ by $46 \%$ (median increase), whereas hyperpolarizing current decreased the firing by $49 \%$ (Fig. 6). The effects of current injection on spike rate persisted throughout each period of current injection, i.e., for an average of

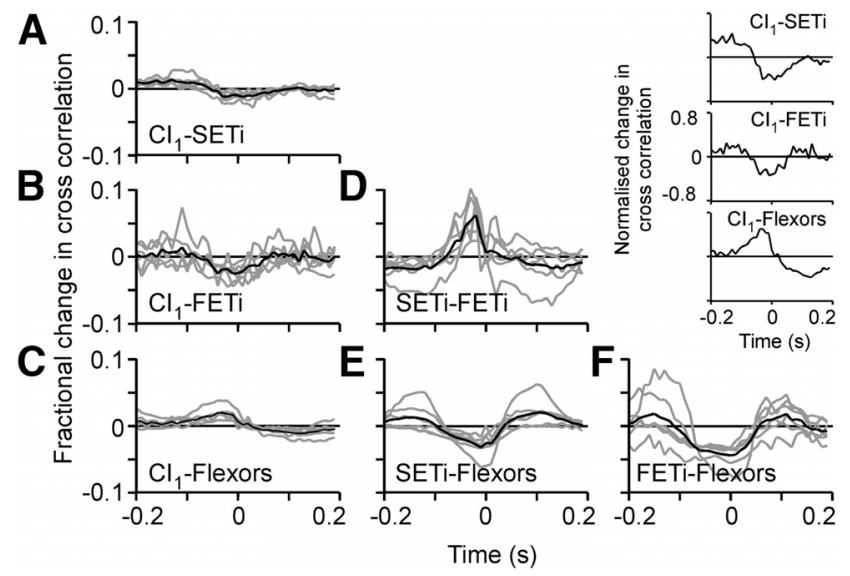

Figure 5. Patterns of excitatory and inhibitory motor activity were related during aimed scratches. Cross-correlations were computed for all combinations of motor activity (see Materials and Methods), and the resulting curves for each of the animals were overlaid (gray curves in $\boldsymbol{A}-\boldsymbol{F}, N=6$ animals). For each combination, a mean curve was also computed (black curves in $\boldsymbol{A}-\boldsymbol{F}) . \boldsymbol{A}, \mathrm{Cl}_{1}$ versus SETi. $\boldsymbol{B}, \mathrm{Cl}_{1}$ versus FETi. $\boldsymbol{C}, \mathrm{Cl}_{1}$ versus flexor motor neurons. $\boldsymbol{D}$, SETi versus FETi. $\boldsymbol{E}$, SETi versus flexor motor neurons. $\boldsymbol{F}$, FETi versus flexor motor neurons. To emphasize the temporal relationships between activity of $\mathrm{Cl}_{1}$ and each of the other motor neuron recordings, the individual cross-correlation plots were also normalized to a peak-to-peak amplitude of 1 and centered before being averaged across animals (inset).

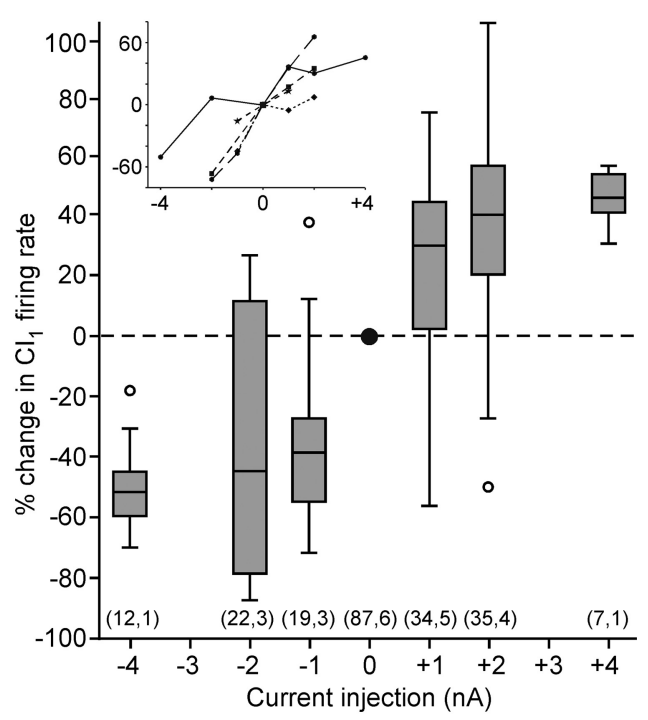

Figure 6. The firing rate of $\mathrm{Cl}_{1}$ could be modified by intracellular current injection during scratching movements. Values are percentage change in firing rate relative to baseline. Numbers in parentheses give the number of scratches and number of animals for each bar. The inset shows the data for the five individual animals plotted separately (different line styles). Inset axes are the same as those of the main figure.

10 min injection for each condition, throughout experiments that lasted for 64-114 min.

\section{$\mathrm{CI}_{1}$ firing rate affects tibial movement velocity}

During nonmanipulated scratching, mean tibial velocity (measured at the distal end of the tibia and averaged across the cyclical part of each scratch) varied widely between 3 and $31 \mathrm{~cm} / \mathrm{s}$. Hyperpolarizing $\mathrm{CI}_{1}$ with -1 to $-4 \mathrm{nA}$ of current caused a $19 \%$ reduction in mean tibial velocity for anterior scratches and a $23 \%$ reduction for posterior scratches.

Femoro-tibial joint angular velocity was also related to $\mathrm{CI}_{1}$ firing rate during both flexion and extension movements of the tibia [ANOVA, all $p<0.001, \mathrm{df}=1$; flexion, $F=66.9$ (depolar- 

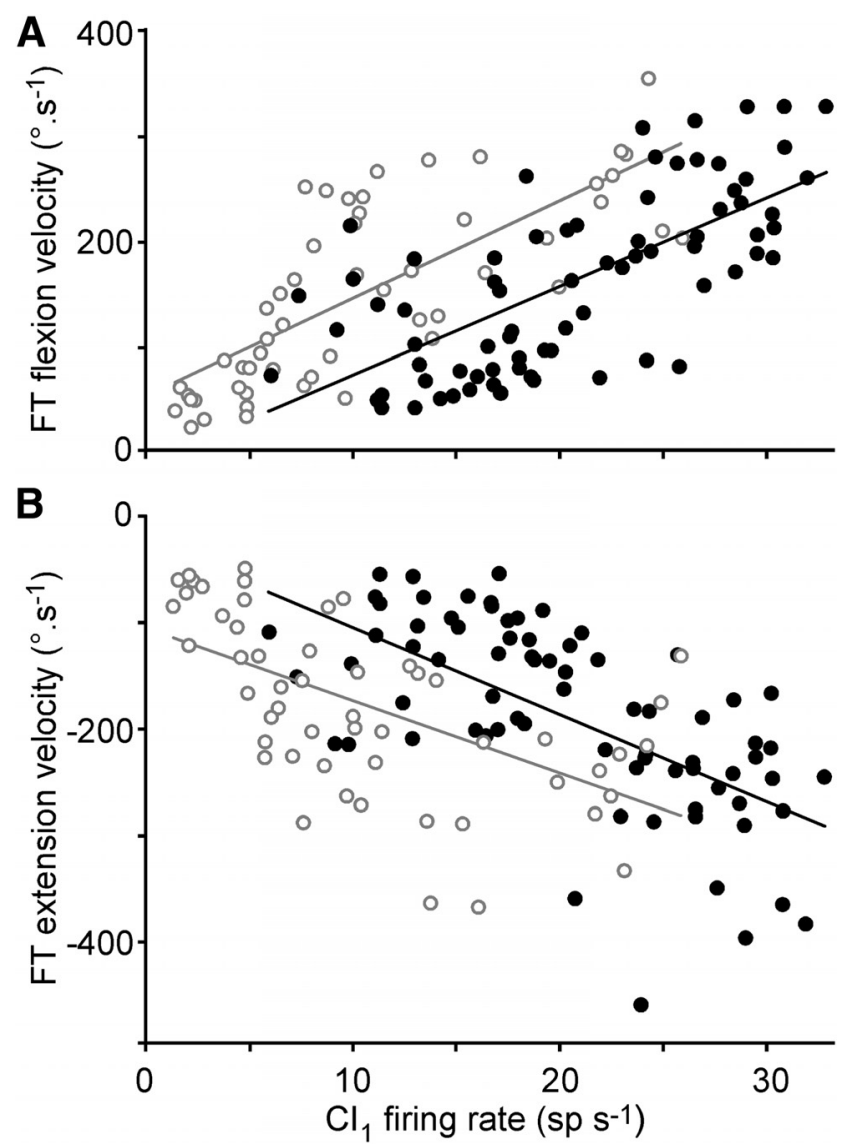

Figure 7. Femoro-tibial (FT) joint angular velocity was related to $\mathrm{Cl}_{1}$ firing rate during aimed scratches. $\mathrm{Cl}_{1}$ firing rate was manipulated by injection of depolarizing current (filled black circles and black regression lines, $1-4 \mathrm{nA}, n=76$ scratches) or hyperpolarizing current (unfilled gray circles and gray regression lines, -4 to $-1 \mathrm{nA}, n=53$ scratches). Each data point represents a scratch. Different levels of hyperpolarization and depolarization were interleaved throughout each experiment, and scratches were elicited at intervals of up to several minutes, so we treated each scratch as an independent observation. Before pooling the data, we first examined the per-animal regressions (20 regressions), which in every case had consistent slopes that were also consistent with the overall slopes of the subsequently pooled data. $\boldsymbol{A}$, Femoro-tibial flexion velocities. Regression through depolarized trials: $y=8.5 x-15.2, r=0.69$. Regression through hyperpolarized trials: $y=9.4 x+49.1, r=0.75$. B, Femoro-tibial extension velocities. Regression through depolarized trials: $y=-8.6 x-18.6, r=0.62$. Regression through hyperpolarized trials: $y=-7.0 x-104.7, r=0.58$. All linear regressions are significant at $p<0.001$ (ANOVA). sp s $^{-1}$, Spikes per second.

ization) and $F=66.7$ (hyperpolarization); extension, $F=46.7$ (depolarization) and $F=26.5$ (hyperpolarization)]. Scratches that were elicited while $\mathrm{CI}_{1}$ was held depolarized by injected current (Fig. 7, solid black symbols) had higher $\mathrm{CI}_{1}$ firing rates and higher femoro-tibial joint angular velocities for both flexion (Fig. 7A) and extension (Fig. 7B) than did scratches elicited while $\mathrm{CI}_{1}$ was held hyperpolarized (Fig. $7 A, B$, open gray symbols). In all cases, there were significant correlations between firing rate and femoro-tibial joint angular velocity (Fig. 7, note that extension velocities are defined as negative, so larger negative values indicate faster extensions). Therefore, $\mathrm{CI}_{1}$ activity contributed to the control of limb velocity during natural movements in locusts. This is consistent with the notion (Wolf, 1990) that, in the absence of compensatory mechanisms, reducing joint stiffness (impedance) should lead to faster movements. The associations between $\mathrm{CI}_{1}$ firing rate and joint velocity were a little stronger for flexion than for extension movements [flexion, $r=$ 0.69 (depolarization) and $r=0.75$ (hyperpolarization); exten-
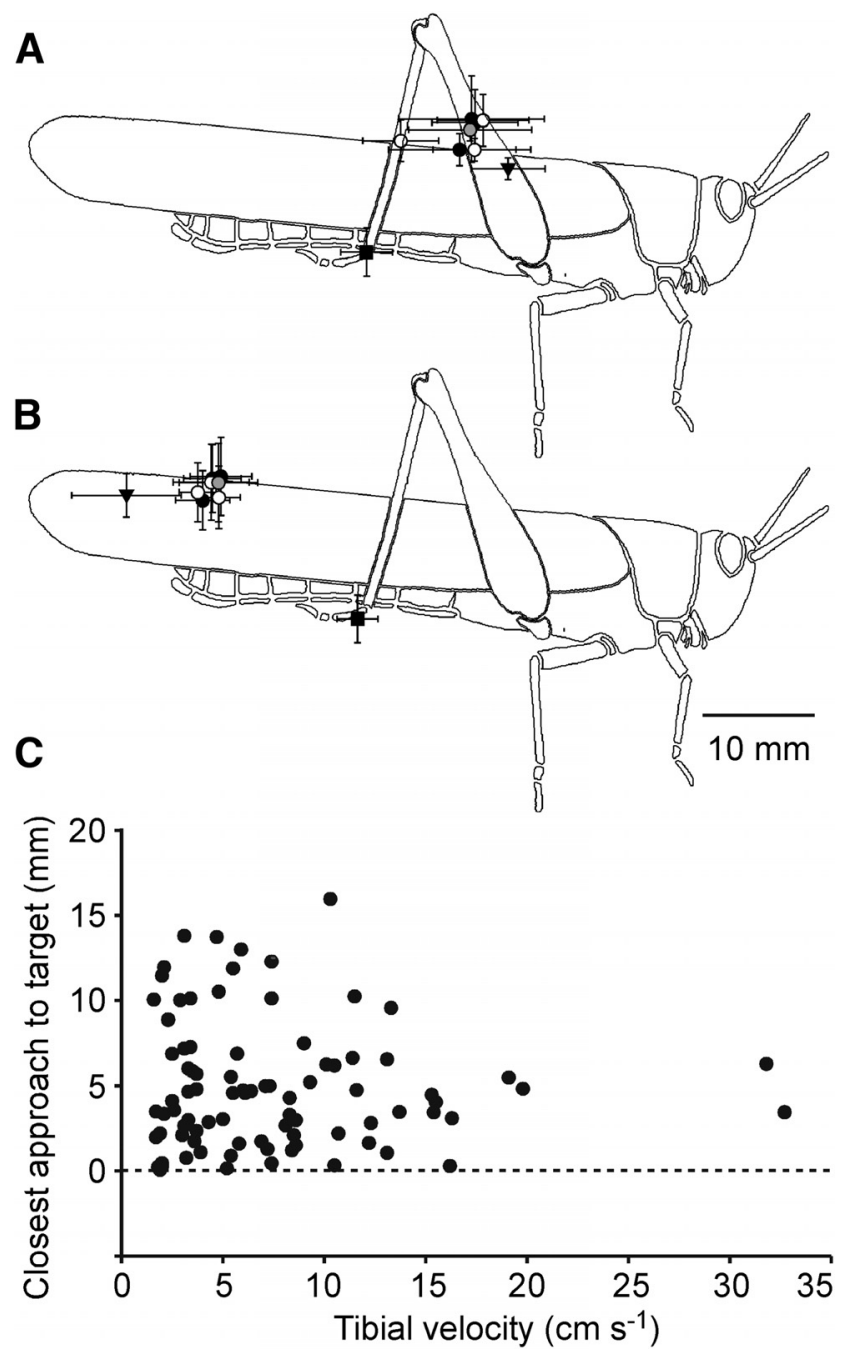

Figure 8. Manipulation of $\mathrm{Cl}_{1}$ firing rate did not affect the accuracy of scratching. Mean $\pm \mathrm{SD}$ stimulation sites are shown as filled triangles for anterior $(\boldsymbol{A})$ and posterior $(\boldsymbol{B})$ scratches. The mean start points are shown as filled squares. The mean closest points of approach of the distal tibia to the stimulus sites were determined separately for each level of current injection in $\mathrm{Cl}_{1}$. Therefore, each circle represents the mean \pm SD coordinates of the closest point of approach for movements made during a particular manipulation of $\mathrm{Cl}_{1}$ in response to stimulation at a particular location on the wing ( $n=1-20$ scratches per condition, $N=1-6$ animals). Gray circles, No manipulation; white circles, injection of hyperpolarizing current $(-4,-3,-2$, and -1 $\mathrm{nA})$; black circles, injection of depolarizing current $(1,2,3$, and $4 \mathrm{nA})$. Animals were upside down when tested but are illustrated upright to facilitate comparisons. $\boldsymbol{C}$, There was no correlation between initial tibial velocity and closest approach to target for 86 control scratches elicited by stimuli to anterior or posterior targets.

sion, $r=0.62$ (depolarization) and $r=0.58$ (hyperpolarization) . For any given firing rate, the femoro-tibial joint velocity was slower for scratches occurring during $\mathrm{CI}_{1}$ depolarization than during hyperpolarization. This is consistent with the assumption that the voluntary synaptic drive onto motor circuits driving scratching is provided in parallel to $\mathrm{CI}_{1}$ and other neurons. An artificial depolarization of $\mathrm{CI}_{1}$ that drove the firing rate upward to a specific value also biased the velocity upward but not as much as natural synaptic inputs that drove $\mathrm{CI}_{1}$ to the same level of firing but also activated other cells simultaneously.

\section{Manipulation of $\mathrm{CI}_{1}$ firing rate does not affect} movement accuracy

The accuracy of scratching movements was determined by measuring the location of the distal end of the tibia at its point of 

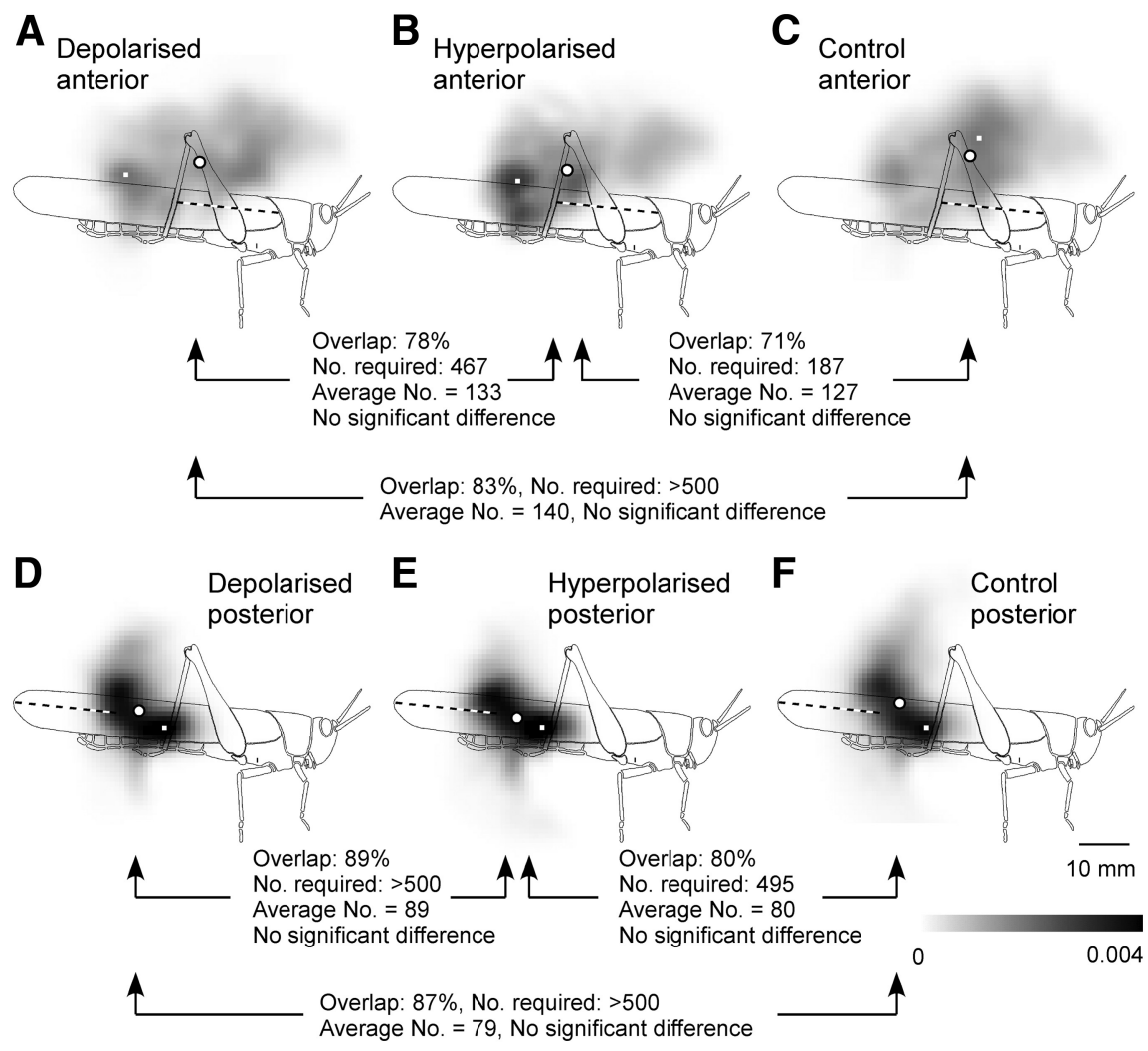

Figure 9. Manipulation of $\mathrm{Cl}_{1}$ firing rate had little or no effect on the area crossed by the distal end of the tibia during scratching Probability distributions are shown for movements aimed at anterior target sites during depolarization $(\boldsymbol{A})$ or hyperpolarization $(\boldsymbol{B})$ of $\mathrm{Cl}_{1}$ and for controls $(\boldsymbol{C})$ and similarly for movements aimed at posterior target sites $(\boldsymbol{D}-\boldsymbol{F})$. Details as for Figure 1. For both anterior and posterior scratches, the movement distributions recorded under all three conditions were very similar. Sample sizes ( $n$ indicates number of scratches): $\boldsymbol{A}, 31 ; \boldsymbol{B}, 17 ; \boldsymbol{C}, 31 ; \boldsymbol{D}, 45 ; \boldsymbol{E}, 35 ; \boldsymbol{F}, 55$.
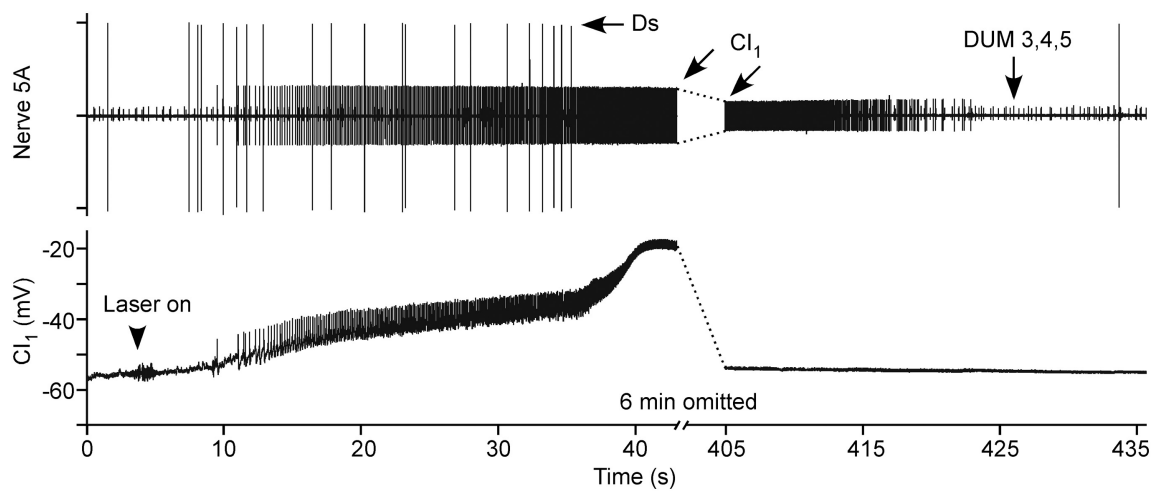

Figure 10. Laser photoablation inactivates $\mathrm{Cl}_{1}$. Intracellular recording from the soma of a dye-filled $\mathrm{Cl}_{1}$ (bottom trace) and an extracellular $\mathrm{N} 5 \mathrm{~A}$ recording containing $\mathrm{Cl}_{1}$ activity monitored from its peripheral axon (medium amplitude spikes) during laser photoablation (arrowhead marks the start of illumination). $\mathrm{Cl}_{1}$ started to fire tonically and then ceased firing after a few minutes. Action potentials disappeared first in the soma and then in the nerve, after a gradual decrease in amplitude. Dotted lines indicate a period of 6 min omitted from this continuous record for clarity. The ongoing firing in Ds was unrelated to the laser illumination.

closest approach to the target (stimulus site; for details, see Materials and Methods). The mean point of closest approach was then determined separately for each combination of stimulus site and level of current injected into $\mathrm{CI}_{1}$. For anterior stimulus sites, the mean points of closest approach were all posterior and dorsal to the target (Fig. 8A). The mean dorsoventral and anteroposterior coordinates of the closest points for the different manipulations of $\mathrm{CI}_{1}$ were not significantly different from those obtained when $\mathrm{CI}_{1}$ was not manipulated [anteroposterior, $-8.4 \pm 5.2 \mathrm{~mm}$ (mean $\pm \mathrm{SD})$, ANOVA, $F=1.66, p=$ 0.143 ; dorsoventral, $13.1 \pm 3.6 \mathrm{~mm}$, Kruskal-Wallis, $H=10.13, p=0.119]$. Manipulating $\mathrm{CI}_{1}$ also had no effect on the point of closest approach for the posterior stimulus site. The mean points were anterior to the target, and their coordinate values were not significantly different from those of nonmanipulated scratches (Fig. $8 B$; anteroposterior, $-30.2 \pm 3.4 \mathrm{~mm}$, ANOVA, $F=0.608, p=0.723$; dorsoventral, $13.1 \pm 3.5 \mathrm{~mm}$, ANOVA, $F=0.716$, $p=0.637)$. There was no correlation between the speed of tibial movement and the closest point of approach to the target in control scratches that encompassed the full range of movement velocities seen for this behavior (Fig. $8 C$; Spearman's rankorder correlation, $r=0.013, p=0.91, n=$ 86 scratches in 6 animals).

Manipulation of $\mathrm{CI}_{1}$ firing rate also had no significant effect on the overall pattern of movement as described by probability density distributions for either anterior (Fig. $9 A-C$ ) or posterior (Fig. $9 D-F)$ scratches. These data indicate that, despite changes in motor inhibition that lead to changes in movement velocity (presumably through changes in joint stiffness), there was no deleterious effect on accuracy as would be expected from a simple speed-accuracy tradeoff.

\section{Photoablation of $\mathrm{CI}_{1}$ reduces movement velocity without compromising accuracy}

Photoablation of $\mathrm{CI}_{1}$ completely silenced spiking activity within a few minutes in all 10 preparations (Fig. 10). Within $20 \mathrm{~s}$ of laser illumination, $\mathrm{CI}_{1}$ membrane potential depolarized and the cell started firing at an increasingly high rate. During continued laser illumination, the cell soma depolarized by $>40 \mathrm{mV}$ and spike amplitude (measured in the soma) declined (Fig. 10). The increased firing rate was evident in the nerve N5A recording of the axonal action potentials, which initially did not change in amplitude (Fig. 10). Nerve $\mathrm{N} 5 \mathrm{~A}$ recordings demonstrated that axonal spikes in $\mathrm{CI}_{1}$ continued for some time, at a reduced amplitude, before also ceasing (Fig. 10). The action potentials of other neurons with axons in N5A were unaffected (Fig. 10). In no case did $\mathrm{CI}_{1}$ resume spontaneous spiking or respond with spikes during subsequent scratching movements. The membrane potential measured at the end of the experiments was $2 \pm 21 \mathrm{mV}(N=8$ of 10 experiments in which reliable measurements could be made at the end).

Inactivation of $\mathrm{CI}_{1}$ caused a significant $28 \%$ decrease in overall tibial velocity (measured at the distal end of the tibia) from 8.2 to $5.9 \mathrm{~cm} / \mathrm{s}$ for anterior scratches and a significant $20 \%$ decrease 

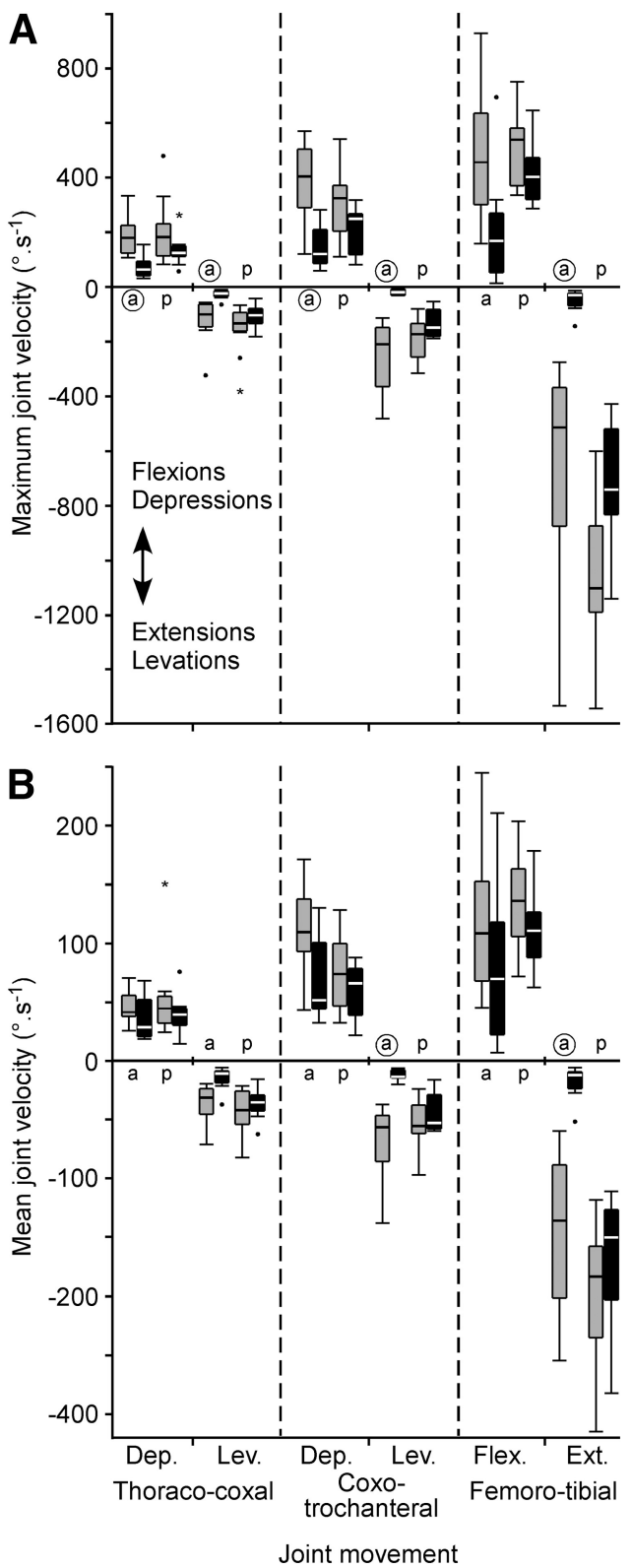

Figure 11. Leg movements are slower after photoablation of $\mathrm{Cl}_{1} . A$, Maximum angular velocities of the thoraco-coxal, coxo-trochanteral, and femoro-tibial joints for scratches aimed at anterior (a) and posterior ( $p$ ) target stimulation sites. Gray bars, $\mathrm{Cl}_{1}$ intact; black bars, $\mathrm{Cl}_{1}$ photoablated. When the reduction in velocity was significant (Mann-Whitney $U$ test with Holm-Bonferroni correction for repeated sampling), the corresponding " $a$ " or " $p$ " is circled. $\boldsymbol{B}$, Mean angular velocities; details as for $A$. Data are from $N=10$ animals, $n=38$ anterior and 114 posterior scratches for $\mathrm{Cl}_{1}$ intact scratches and 64 anterior and 157 posterior scratches for $\mathrm{Cl}_{1}$ photoablated. Dep, Depression; Lev, levation; Flex, flexion; Ext, extension. Levation and extension velocities are negative by definition. Therefore, larger negative values indicate faster levations and extensions. Larger positive values indicate faster depressions and flexions. Asterisks indicate extreme outliers ( $>3$ times interquartile range).

from 10.9 to $8.7 \mathrm{~cm} / \mathrm{s}$ for posterior scratches (Mann-Whitney rank-sum test; anterior, $U=696.5, p=0.004, n=38$ control and 64 postablation scratches; posterior, $U=6713.5, p<0.019, n=$ 114 control and 157 postablation scratches). In five control locusts, $\mathrm{CI}_{1}$ was recorded but not photoablated, and, in these animals, there was no change in overall tibial velocity over the course of the experiment (mean velocity of scratches made at the end of the experiment was $99 \pm 13 \%$ of the velocity at the beginning).

The overall decrease in tibial velocity was driven by reductions

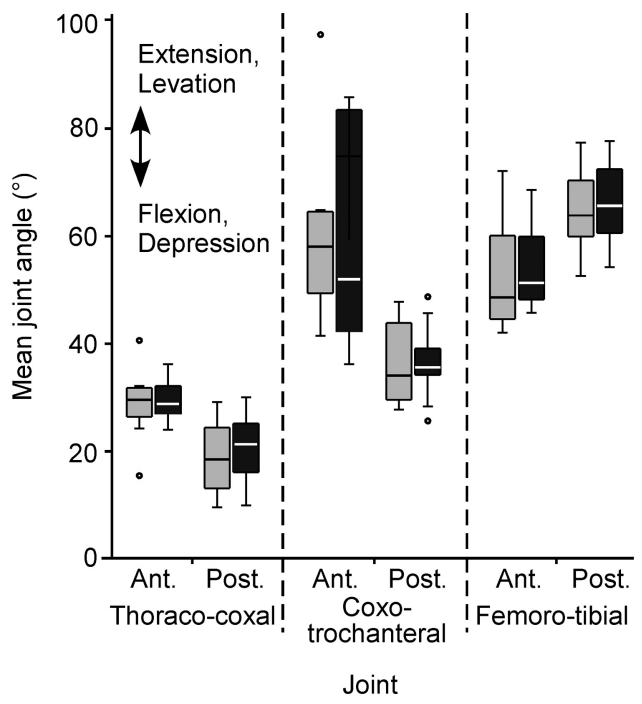

Figure 12. Photoablation of $\mathrm{Cl}_{1}$ did not alter mean joint angles of scratches. Measurements of thoraco-coxal, coxo-trochanteral, and femoro-tibial joint angles for movements aimed at anterior (Ant.) and posterior (Post.) target sites before (gray bars) and after (black bars) $\mathrm{Cl}_{1}$ photoablation. Sample sizes as for Figure 11.

in both mean and maximum angular velocity at all three proximal joints (Fig. 11). The effects were generally more pronounced for anterior scratches and included reductions in both extension and flexion velocities at the femoro-tibial joint and in both depression and levation velocities at the thoraco-coxal and coxotrochanteral joints (Fig. 11). In every case, joint angular velocity was lower after $\mathrm{CI}_{1}$ photoablation (median values in black bars are smaller than those in corresponding gray bars in all 24 comparisons shown in Fig. 11), although many of the comparisons were not significant. The circled "a" letters in Figure 11 indicate where these differences were significant for anterior scratches (none were significant for posterior scratches). Data were tested using Mann-Whitney rank-sum tests with Holm-Bonferroni correction for repeated testing. At the femoro-tibial joint, for example, photoablation of $\mathrm{CI}_{1}$ caused a significant $95 \%$ decrease in maximum extension velocity from -517 to $-27 \%$ s (median values) in anterior scratches and a nonsignificant $33 \%$ decrease from -1108 to $-747^{\circ} / \mathrm{s}$ in posterior scratches (Fig. 11A). Maximum flexion velocities in both cases also appeared to be lower after $\mathrm{CI}_{1}$ photoablation, but these differences were not significant. The same pattern was seen for mean femoro-tibial joint velocities in these same movements (Fig. 11B). For all three joints, the relative change in velocity after $\mathrm{CI}_{1}$ photoablation was always greater for anterior than posterior scratches (Fig. 11A,B), which may be related to the different ranges of joint angle used in each case (see below, next paragraph). In five control locusts, $\mathrm{CI}_{1}$ was recorded but not photoablated, and, in these animals, there was no change in joint angular velocity over the course of the experiment (overall joint angular velocity of scratches made at the end of the experiment was $107 \pm 33 \%$ of the value at the beginning: all joints pooled).

The thoraco-coxal, coxo-trochanteral, and femoro-tibial joints all had characteristically different mean angles for anterior and posterior scratches, reflecting the different trajectories of the movements (Fig. 4). For example, the femoro-tibial joint was $15^{\circ}$ more flexed during anterior scratches than during posterior scratches (Fig. 12, median values). Despite the pronounced changes in movement velocities after $\mathrm{CI}_{1}$ photoablation, mean joint angles were unaffected by the loss of $\mathrm{CI}_{1}$ (Fig. 12: Mann- 
A

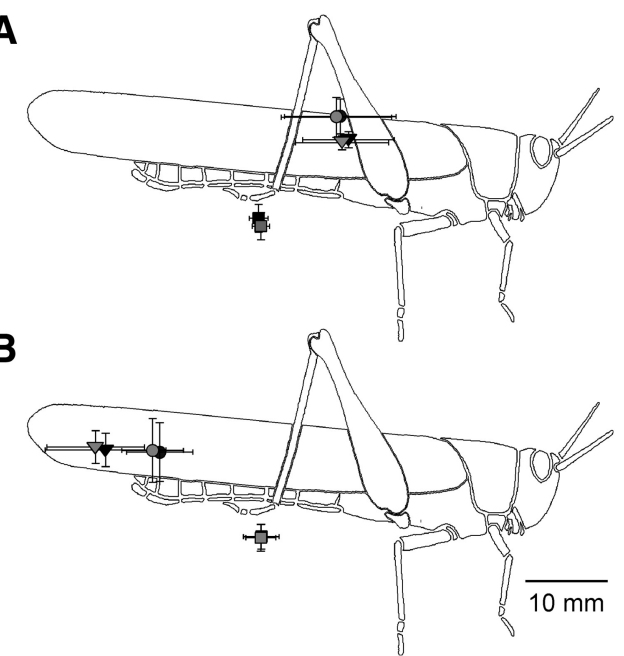

Figure 13. Photoablation of $\mathrm{Cl}_{1}$ did not alter tibial accuracy. Circles indicate the mean $\pm \mathrm{SD}$ closest points of approach of the tibia to anterior $(\boldsymbol{A})$ and posterior $(\boldsymbol{B})$ stimulus sites. Closest points were determined before (gray circles) and after (black circles) $\mathrm{Cl}_{1}$ photoablation. Gray and black squares indicate the corresponding mean $\pm S D$ stimulus site. Gray and black squares indicate the mean \pm SD starting positions. Sample sizes as for Figure 11 .
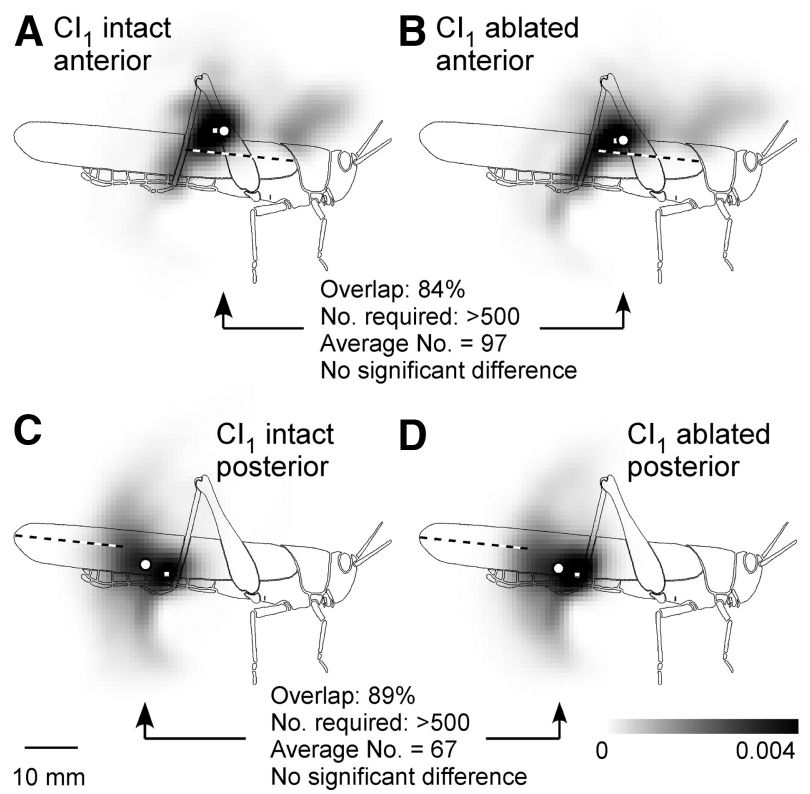

Figure 14. Photoablation of $\mathrm{Cl}_{1}$ had no effect on the overall area crossed by the distal end of the tibia during scratching. Probability distributions are shown for movements aimed at anterior target sites before $(\boldsymbol{A})$ and after $(\boldsymbol{B}) \mathrm{Cl}_{1}$ photoablation and for movements aimed at posterior target sites before $(\boldsymbol{C})$ and after $(\boldsymbol{D}) \mathrm{Cl}_{1}$ photoablation. Details as for Figure 1. For both anterior and posterior scratches, the movement distributions recorded before and after $\mathrm{Cl}_{1}$ photoablation were highly similar. Sample sizes as for Figure 11.

Whitney rank-sum tests yielded $p>0.46$ for all comparisons). Photoablation of $\mathrm{CI}_{1}$ also had no effect on the closest point of approach made by the distal end of the tibia to the target, for either anterior scratches (Fig. 13A: Mann-Whitney rank-sum test, $U=1152.5, p=0.663, n=38$ control and 64 postablation scratches) or posterior scratches (Fig. 13B: Mann-Whitney ranksum test, $U=7986.5, p=0.131, n=114$ control and 157 postablation scratches). Similarly, the overall form of the movement, represented by the probability density map for distal tibial locations, was unaffected by photoablation of $\mathrm{CI}_{1}$ activity for either anterior (Fig. $14 A, B$ ) or posterior (Fig. $14 C, D$ ) scratches. In both cases, the patterns of movement before and after $\mathrm{CI}_{1}$ ablation had extremely high levels of overlap ( $84 \%$ for anterior and $89 \%$ for posterior scratches). These data indicate that the complete loss of a key inhibitory motor neuron that is used to regulate limb movement velocity does not concomitantly compromise movement accuracy.

\section{Discussion}

Modulating the activity of one common inhibitory motor neuron in an insect affects the speed of aimed limb movements but not their pattern. Therefore, inhibition can permit insects to reduce joint stiffness — and thus make faster movements (Wolf, 1990) without trading this off against lower accuracy.

\section{Patterned inhibitory motor activity is integral to natural scratching movements}

We show that orientation has no effect on the overall area crossed by the tibia or on the speed of natural aimed movements. This is in part a consequence of the light weight of the limb, which means that both active muscle forces and passive forces intrinsic to the limb are sufficiently strong to maintain the femoro-tibial joint (and perhaps other joints) at a gravity-independent posture without changes to, or even in the absence of, motor activity (Zakotnik et al., 2006; Hooper et al., 2009; Ache and Matheson, 2012, 2013). We demonstrate that inhibitory motor activity is closely integrated with excitatory motor activity that drives aimed limb movements. Activity in $\mathrm{CI}_{1}$ increases before movement, is modulated in time with the scratching rhythm, and declines gradually throughout a scratch. In walking locusts, all three common inhibitor motor neurons are depolarized throughout the walking sequence and modulated similarly in the step cycle, with highest activity during leg protraction when the leg is off the ground (Wolf, 1990). In scratching locusts, $\mathrm{CI}_{1}$ activity is higher during periods when the flexor tibiae motor neurons are active, which is consistent with a role in reducing residual resistive forces in the large extensor tibiae muscle (Pearson and Bergman, 1969; Usherwood and Runion, 1970; Pearson, 1973; Watson et al., 1985; Wolf, 1990; Schmidt and Rathmayer, 1993; Duch and Pflüger, 1995; Schmäh and Wolf, 2003).

\section{Inhibitory motor activity affects the speed of movements without affecting accuracy}

We examined the effect of motor inhibition on movement accuracy by depolarizing, hyperpolarizing, or killing $\mathrm{CI}_{1}$ to control its firing rate. Polarization by up to $\pm 4 \mathrm{nA}$ modulated $\mathrm{CI}_{1}$ firing by approximately $\pm 50 \%$, and killing the cell removed all firing. The effects of hyperpolarization and photoablation on movements were essentially the same. Manipulating the activity of $\mathrm{CI}_{1}$ had no effect on the overall pattern of movement of the leg or on movement accuracy. This lack of effect on accuracy is unexpected, because removal of inhibitory motor activity is thought to increase joint stiffness (Wolf, 1990) and, particularly at the femorotibial joint in which $\mathrm{CI}_{1}$ innervates only one antagonist muscle, might be expected to bias movement trajectories. The stability of the movement pattern despite altered muscle properties is likely to be governed by two complementary mechanisms. First, proprioceptive signals provide position-control feedback (Page and Matheson, 2009). In the stick insect, such feedback controls the "anterior extreme position" achieved by a limb swinging forward in stance phase, whereas the velocity of swing is governed by other mechanisms (Dean and Cruse, 1986). Second, spring-like passive forces arising in the muscles, tendons, or the joints themselves act 
to return the limb to a central posture in the absence of active muscle contractions (Zakotnik et al., 2006; Hooper et al., 2009; Ache and Matheson, 2012, 2013). These stabilizing forces increase as limb joint angles approach their physical limits and can generate return movements that are as fast as active, muscledriven movements (Ache and Matheson, 2013). Thus, they provide a mechanism that could damp extreme movements that might otherwise result from the lowering of muscle-derived stiffness after activity of the common inhibitory motor neurons.

The locust hindleg is innervated by three common inhibitory motor neurons. Photoablation of just one of them, $\mathrm{CI}_{1}$, led to a $28 \%$ decrease in tibial velocity for anterior scratches and hyperpolarization to a $19 \%$ decrease. For posterior scratches, the corresponding reductions were 20 and $23 \%$. These data suggest that small modulations of $\mathrm{CI}_{1}$ firing rate (e.g., those caused by hyperpolarization) account for most of the effect of $\mathrm{CI}_{1}$ on movement velocity, which is consistent with the demonstration by Wolf (1990) that a single $\mathrm{CI}_{1}$ spike caused a $10 \%$ increase in leg protraction velocity. In walking animals, leg contact with the substratum during retraction results in strong interleg coupling and precludes a complete analysis of the overall effect of inhibitory activity (Wolf, 1990). By using a different behavior, scratching, in which there is no interleg coupling or external loading, we showed that a single common inhibitory motor neuron influences both extension and flexion velocities at all main joints of the limb. Common inhibitor motor neurons increase movement velocities by preventing the buildup of residual tension in muscles opposing the movement and by enhancing their rates of relaxation (Pearson, 1973; Ballantyne and Rathmayer, 1981; Rathmayer and Erxleben, 1983; Wolf, 1990). These effects are mediated by presynaptic inhibition of SETi and by direct inhibition of slow extensor tibiae muscle fibers. Our experiments did not distinguish between these mechanisms. Dynamic control of residual tension is likely to be of greater importance for invertebrates and small vertebrates in which limb masses and inertias are small than for larger heavier vertebrates in which the influences of gravity and inertia predominate (Hooper et al., 2009). Although $\mathrm{CI}_{1}$ does not innervate the flexor tibiae muscle, we show that $\mathrm{CI}_{1}$ activity nevertheless enhances femoro-tibial extension velocity. This effect must be mediated indirectly: during a rhythmical scratch, $\mathrm{CI}_{1}$-mediated reductions in extensor tibiae residual forces likely permit the flexor tibiae muscle to operate with lower active forces, in turn reducing its buildup of residual passive forces that would impede extensions. This interpretation is consistent with the demonstration that long force decay times in the locust lead to substantial co-contraction and high joint stiffness, although the bursts of motor activity driving antagonists have little overlap (Zakotnik et al., 2006). In denervated locust hindlegs, passive forces in the much larger extensor tibiae muscle dominate over those in the smaller flexor tibiae to the extent that complete removal of the flexor has little effect on the resting angle of the joint (Burrows and Horridge, 1974; Ache and Matheson, 2012). We now show that the extensor tibiae also has an important role in regulating both extension and flexion velocity in active movements. This effect may be enhanced by firing of $\mathrm{CI}_{2}$ and $\mathrm{CI}_{3}$, which do innervate the flexor and can be active in concert with $\mathrm{CI}_{1}$ (Wolf, 1990). The lack of correlation between movement speed and accuracy for a wide range of natural aimed movements suggests that concerted changes in firing in all three common inhibitors also do not affect accuracy. Common inhibition in arthropods, by virtue of influencing sets of muscles acting at different joints, may provide a mechanism for regulating endpoint impedance that in vertebrates can only be achieved by poly- articular muscles. Such coordination is thought to simplify overall movement control (Hogan, 1985). CI $_{1}$ activity before anteriorly directed movement onset was twice as high as that preceding posterior movements, suggesting that limb stiffness is modulated differentially to account for different limb configurations. In a similar way, joint stiffness in humans was proposed to be modulated so as to have a fixed relation to endpoint inertia that differs for different arm configurations (Mussa-Ivaldi et al., 1985).

In humans and other large vertebrates, increases in joint stiffness permit more accurate movements by filtering out motor noise and stabilizing the limb against joint interaction torques, both of which increase with velocity, and against external perturbations (Hogan, 1985; Gribble et al., 2003; Popescu et al., 2003; Osu et al., 2004; Selen et al., 2006, 2009; Wong et al., 2009). In contrast, we show that, in an insect, imposed changes of motor inhibition (which regulate muscle contraction and relaxation properties), although having marked effects on movement velocity, do not compromise accuracy. The reduction in limb stiffness caused by common inhibition might be energy efficient, providing a parallel to the observation that humans prefer to modulate movement speed rather than co-contract limb muscles to enhance accuracy (Missenard and Fernandez, 2011). However, a key difference may be the relatively larger contributions of passive joint forces to overall joint stiffness in the relatively light limbs of insects compared with the heavy limbs of large vertebrates. In particular, for the locust hindleg, it is passive joint forces and not passive flexor muscle force that generate rapid flexions from the most extreme extended angles (Ache and Matheson, 2013). These forces are independent of muscle contraction/relaxation properties and do not act through the muscle tendons. Therefore, they contribute a predictable joint stiffness that increases as the femoro-tibial joint extends out of the preferred midrange of angles used for most scratching movements. We propose that these passive joint forces exert a controlling influence on movement accuracy that is unaffected by activity of the common inhibitors. In contrast, within the midranges of movement used to reach most targets, passive joint forces are small, so that muscle forces and co-contraction (both of which are influenced by inhibition) dominate. Within these ranges of joint angle, changes of joint stiffness, including those brought about by the actions of the common inhibitors, can act to regulate movement velocity.

\section{References}

Ache JM, Matheson T (2012) Passive resting state and history of antagonist muscle activity shape active extensions in an insect limb. J Neurophysiol 107:2756-2768. CrossRef Medline

Ache JM, Matheson T (2013) Passive joint forces are tuned to limb use in insects and drive movements without motor activity. Curr Biol 23:14181426. CrossRef Medline

Ballantyne D, Rathmayer W (1981) On the function of the common inhibitory neurone in the walking legs of the crab, Eriphia spinifrons. J Comp Physiol A 143:111-122. CrossRef

Bässler D, Rathmayer W (1996) Photoinactivation of an identified motoneurone in the locust Locusta migratoria. J Exp Biol 199:2369-2382. Medline

Berkowitz A, Laurent G (1996a) Local control of leg movements and motor patterns during grooming in locust. J Neurosci 16:8067-8078. Medline

Berkowitz A, Laurent G (1996b) Central generation of grooming motor patterns and interlimb coordination in locusts. J Neurosci 16:8079-8091. Medline

Braunig P (1997) The peripheral branching pattern of identified dorsal unpaired median (DUM) neurones of the locust. Cell Tissue Res 290:641654. CrossRef Medline

Braunig P, Eder M (1998) Locust dorsal unpaired median (DUM) neurones 
directly innervate and modulate hindleg proprioceptors. J Exp Biol 201: 3333-3338. Medline

Burrows M (1996) The neurobiology of an insect brain. Oxford, UK: Oxford UP.

Burrows M, Horridge GA (1974) The organization of inputs to motoneurons of the locust metathoracic leg. Philos Trans R Soc Lond B Biol Sci 269:49-94. CrossRef Medline

Büschges A, Djokaj S, Bässler D, Bässler U, Rathmayer W (2000) Neuromuscular plasticity in the locust after permanent removal of an excitatory motoneuron of the extensor tibiae muscle. J Neurobiol 42:148-159. CrossRef Medline

Dean J, Cruse H (1986) Evidence for the control of velocity as well as position in leg protraction and retraction by the stick insect. Exp Brain Res 15:263-274.

Duch C, Pflüger HJ (1995) Motor patterns for horizontal and upside-down walking and vertical climbing in the locust. J Exp Biol 198:1963-1976. Medline

Dürr V, Matheson T (2003) Graded limb targeting in an insect is caused by the shift of a single movement pattern. J Neurophysiol 90:1754-1765. CrossRef Medline

Fitts PM (1954) The information capacity of the human motor system in controlling the amplitude of movement. J Exp Psychol 47:381-391. CrossRef Medline

Gribble PL, Mullin LI, Cothros N, Mattar A (2003) Role of cocontraction in arm movement accuracy. J Neurophysiol 89:2396-2405. CrossRef Medline

Hale JP, Burrows M (1985) Innervation patterns of inhibitory motor neurones in the thorax of the locust. J Exp Biol 117:401-413. Medline

Hogan N (1985) The mechanics of multi-joint posture and movement control. Biol Cybern 52:315-331. CrossRef Medline

Hooper SL, Guschlbauer C, Blümel M, Rosenbaum P, Gruhn M, Akay T, Büschges A (2009) Neural control of unloaded leg posture and of leg swing in stick insect, cockroach, and mouse differs from that in larger animals. J Neurosci 29:4109-4119. CrossRef Medline

Hoyle G (1955a) The anatomy and innervation of locust skeletal muscle. Proc R Soc Lond B Biol Sci 143:281-292. CrossRef Medline

Hoyle G (1955b) Neuromuscular mechanism of a locust skeletal muscle. Proc R Soc Lond B Biol Sci 143:343-367. CrossRef Medline

Hoyle G (1978) Distributions of nerve and muscle fibre types in locust jumping muscle. J Exp Biol 73:205-233. Medline

Matheson T (1997) Hindleg targeting during scratching in the locust. J Exp Biol 200:93-100. Medline

Matheson T (1998) Contralateral coordination and retargeting of limb movements during scratching in the locust. J Exp Biol 201:2021-2032. Medline

Matheson T, Dürr V (2003) Load compensation in targeted limb movements of an insect. J Exp Biol 206:3175-3186. CrossRef Medline

Miller JP, Selverston A (1979) Rapid killing of single neurons by irradiation of intracellularly injected dye. Science 206:702-704. CrossRef Medline

Missenard O, Fernandez L (2011) Moving faster while preserving accuracy. Neuroscience 197:233-241. CrossRef Medline

Mussa-Ivaldi FA, Hogan N, Bizzi E (1985) Neural, mechanical, and geometric factors subserving arm posture in humans. J Neurosci 5:2732-2743. Medline

Osu R, Kamimura N, Iwasaki H, Nakano E, Harris CM, Wada Y, Kawato M (2004) Optimal impedance control for task achievement in the presence of signal-dependent noise. J Neurophysiol 92:1199-1215. CrossRef Medline

Page KL, Matheson T (2004) Wing hair sensilla underlying aimed hindleg scratching of the locust. J Exp Biol 207:2691-2703. CrossRef Medline

Page KL, Matheson T (2009) Functional recovery of aimed scratching movements after a graded proprioceptive manipulation. J Neurosci 29: 3897-3907. CrossRef Medline

Page KL, Zakotnik J, Dürr V, Matheson T (2008) Motor control of aimed limb movements in an insect. J Neurophysiol 99:484-499. CrossRef Medline

Pearson KG (1973) Function of peripheral inhibitory axons in insects. Am Zool 13:321-330.

Pearson KG, Bergman SJ (1969) Common inhibitory motoneurones in insects. J Exp Biol 50:445-471. Medline

Pearson KG, Robertson RM (1981) Interneurons coactivating hindleg flexor and extensor motoneurons in the locust. J Comp Physiol A 144: 391-400. CrossRef

Popescu F, Hidler JM, Rymer WZ (2003) Elbow impedance during goaldirected movements. Exp Brain Res 152:17-28. CrossRef Medline

Rathmayer W, Erxleben C (1983) Identified muscle fibres in a crab. I. Characteristics of excitatory and inhibitory neuromuscular transmission. J Comp Physiol 152:411-420. CrossRef

Ryckebusch S, Laurent G (1993) Rhythmic patterns evoked in locust leg motor neurons by the muscarinic agonist pilocarpine. J Neurophysiol 69:1583-1595. Medline

Sasaki K, Burrows M (1998) Innervation pattern of a pool of nine excitatory motor neurons in the flexor tibiae muscle of a locust hind leg. J Exp Biol 201:1885-1893. Medline

Schmäh M, Wolf H (2003) Inhibitory motor neurones supply body wall muscles in the locust abdomen. J Exp Biol 206:445-455. CrossRef Medline

Schmidt J, Rathmayer W (1993) Central organization of common inhibitory motoneurons in the locust: role of afferent signals from leg mechanoreceptors. J Comp Physiol A 172:447-456. CrossRef

Selen LPJ, Beek PJ, van Dieën JH (2006) Impedance is modulated to meet accuracy demands during goal-directed arm movements. Exp Brain Res 172:129-138. CrossRef Medline

Selen LP, Franklin DW, Wolpert DM (2009) Impedance control reduces instability that arises from motor noise. J Neurosci 29:12606-12616. CrossRef Medline

Usherwood PNR, Grundfest H (1964) Inhibitory postsynaptic potentials in grasshopper muscle. Science 143:817-818. CrossRef Medline

Usherwood PNR, Grundfest H (1965) Peripheral inhibition in skeletal muscle of insects. J Neurophysiol 28:497-518. Medline

Usherwood PNR, Runion HI (1970) Analysis of the mechanical responses of metathoracic extensor tibiae muscles of free-walking locusts. J Exp Biol 53:39-58.

Watson AHD, Burrows M, Hale JP (1985) The morphology and ultrastructure of common inhibitory motor neurones in the thorax of the locust. J Comp Neurol 239:341-359. CrossRef Medline

Wiersma CAG, Ripley SH (1952) Innervation patterns of crustacean limbs. Physiologica Comp Oecol 2:391-405.

Wolf H (1990) Activity patterns of inhibitory motoneurones and their impact on the leg movement in tethered walking locusts. J Exp Biol 152:281-304.

Wong J, Wilson ET, Malfait N, Gribble PL (2009) Limb stiffness is modulated with spatial accuracy requirements during movement in the absence of destabilizing forces. J Neurophysiol 101:1542-1549. CrossRef Medline

Woodworth RS (1899) The accuracy of voluntary movement. Psychol Rev Monogr Suppl 3:1-114.

Zakotnik J, Matheson T, Dürr V (2004) A posture optimization algorithm for model-based motion capture of movement sequences. J Neurosci Methods 135:43-54. CrossRef Medline

Zakotnik J, Matheson T, Dürr V (2006) Co-contraction and passive forces facilitate load compensation of aimed limb movements. J Neurosci 26: 4995-5007. CrossRef Medline 